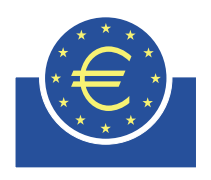

EUROPEAN CENTRAL BANK

OCCASIONAL PAPER SERIES

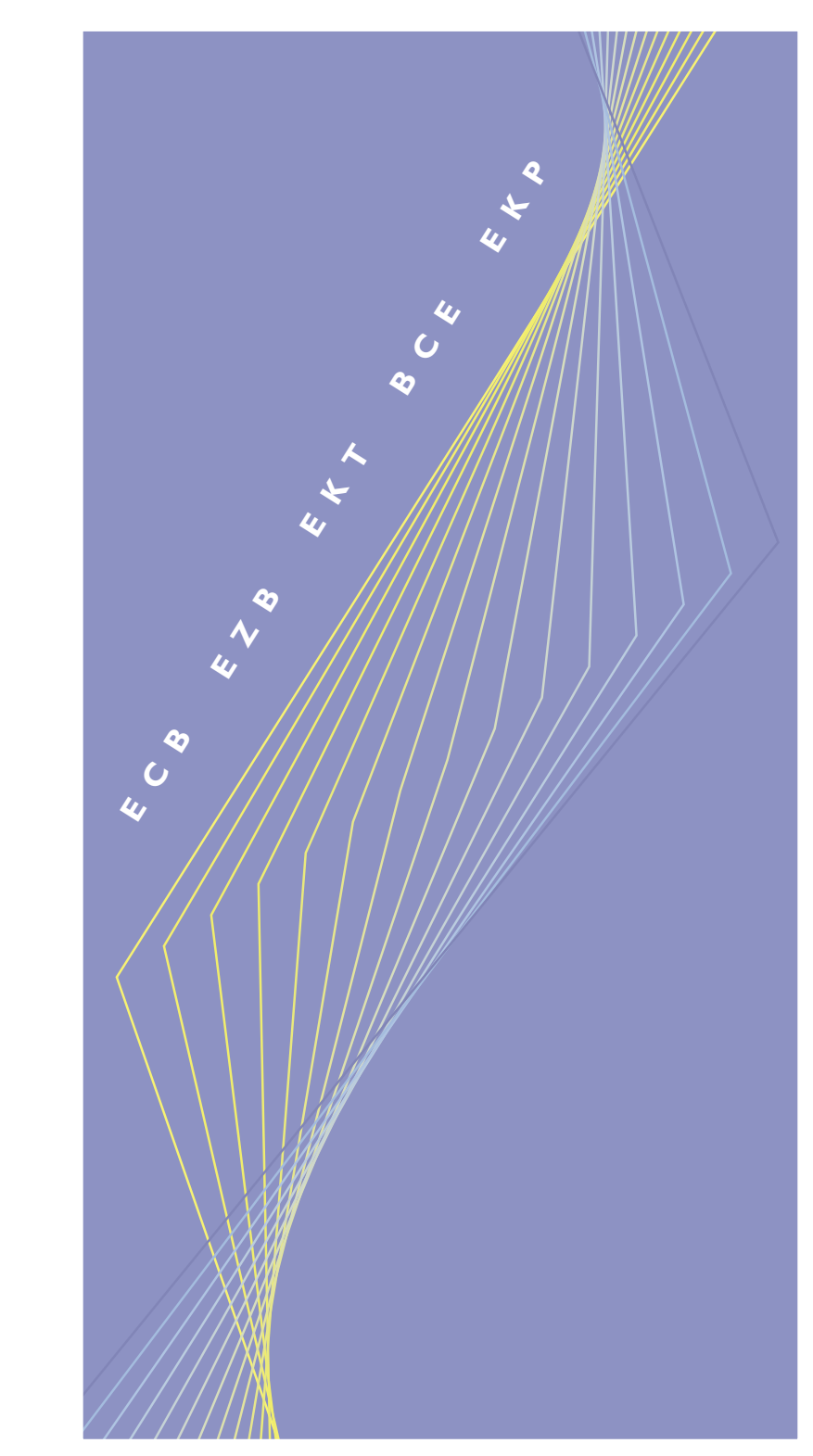

NO. 8

\title{
AN INTRODUCTION TO THE ECB'S SURVEY OF \\ PROFESSIONAL FORECASTERS
}

B Y

JUAN ANGEL GARCIA

SEPTEMBER 2003 



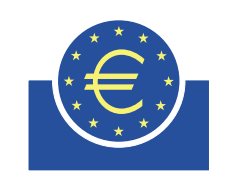

E U R P E A C E N TRAL BA N K

OCCASIONAL PAPER SERIES

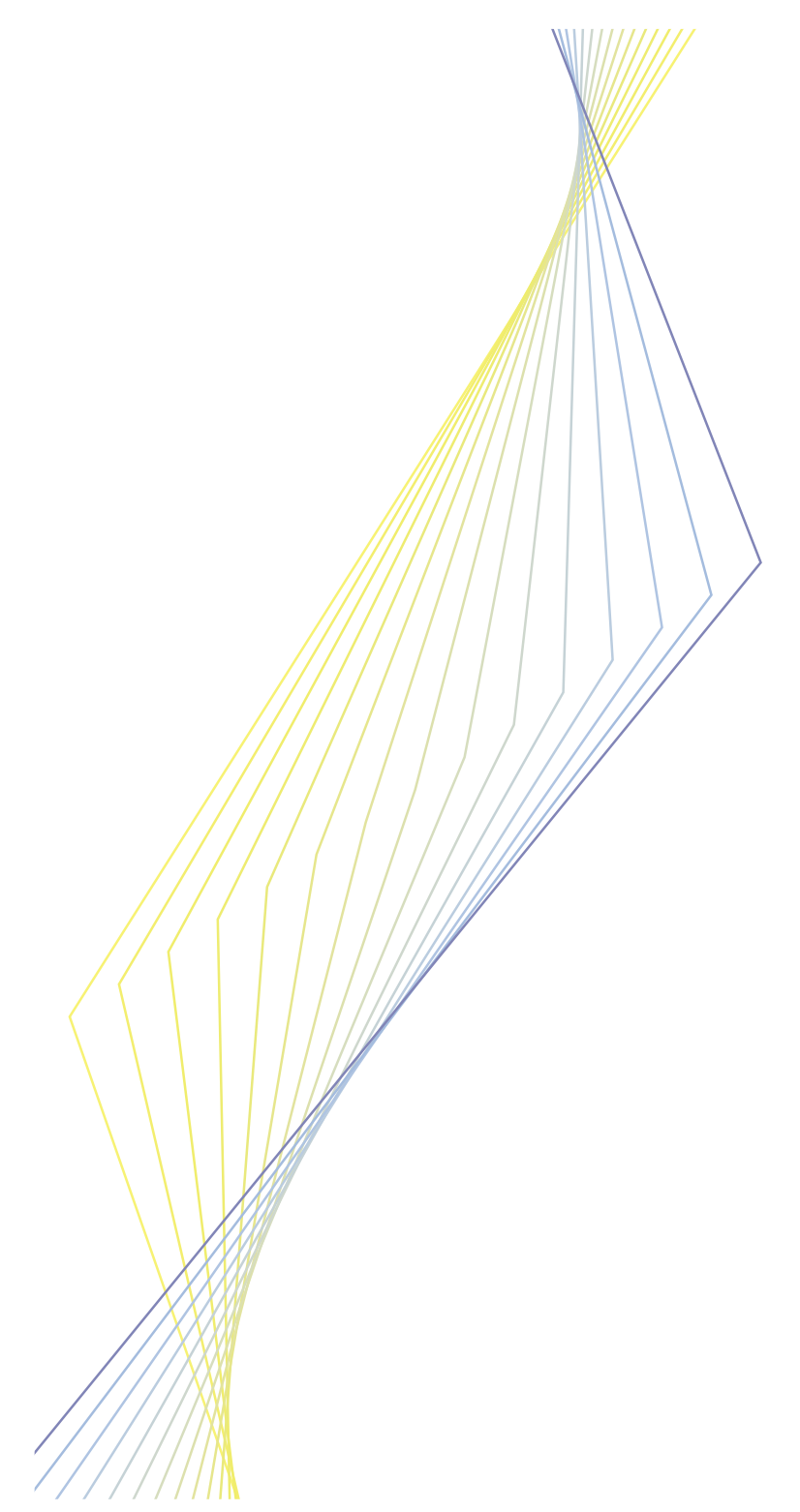

NO. 8

\title{
AN INTRODUCTION TO THE ECB'S SURVEY OF \\ PROFESSIONAL FORECASTERS
}

B Y

\author{
JUAN ANGEL GARCIA
}

SEPTEMBER 2003 
(C) European Central Bank, 2003

Address

Kaiserstrasse 29

603 II Frankfurt am Main

Germany

Postal address

Postfach 160319

60066 Frankfurt am Main

Germany

$+496913440$

Telephone

http://www.ecb.int

Internet

$+496913446000$

Fax

4 II 144 ecb d

Telex

The views expressed in this paper do not necessarily reflect those of the European Central Bank.

All rights reserved.

Reproduction for educational and non-commercial purposes is permitted provided that the source is acknowledged.

ISSN 1607-1484 (print)

ISSN 1725-6534 (online) 


\section{Table of contents}

Executive summary

I Introduction

II The motivations for the ECB's Survey of Professional Forecasters

III An overview of the ECB's Survey of Professional Forecasters

I The SPF questionnaire $\quad 8$

2 The panel of forecasters 1 I

3 Participation 12

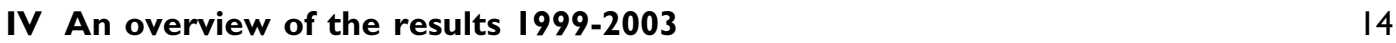

$\begin{array}{lll}\text { I Inflation expectations } & 14\end{array}$

2 Growth expectations 19

3 Unemployment expectations 21

4 The relationships between the expectations for the different variables:

a tentative exploration $\quad 22$

$\begin{array}{ll}\text { V Concluding remarks } & 25\end{array}$

Annex I Changes in the uncertainty surrounding the mean expectations over time 26

Annex II Other available surveys similar to the ECB's SPF 29

Annex III Historical values of the mean point estimates and the aggregate results of the 2003 Q2 SPF 


\section{Executive summary}

Since 1999 the European Central Bank (ECB) has conducted a quarterly survey of expectations for some of the euro area key macroeconomic variables. The survey is known as the ECB's Survey of Professional Forecasters (SPF) to reflect the fact that all of the survey participants are experts affiliated with financial or non-financial institutions based within the European Union (EU). The SPF questionnaire includes questions on expectations for HICP (Harmonised Index of Consumer Prices) inflation, the real GDP growth rate and the unemployment rate in the euro area over different horizons, as well as questions seeking to quantify the uncertainty surrounding these variables. Aggregate results for each variable and horizon are compiled by the $E C B$ on the basis of the individual replies. A brief summary of these results is currently published in a regular box in the ECB's
Monthly Bulletin soon after the survey rounds have been completed. From October 2003, the aggregate results for the most recent survey round will appear simultaneously in a box in the Monthly Bulletin and on the SPF webpages in the Statistics section of the ECB's website (http://www.ecb.int/stats/spf). The historical dataset comprising the aggregate results of all the survey rounds conducted to date will also be available on the SPF webpages from October 2003.

This paper begins by explaining why the ECB decided to launch the SPF. It then provides an overview of the survey, looking at the design and content of the SPF questionnaire, the composition of the panel of forecasters and the participation in the survey. It then describes some of the salient features of the results of the first 18 survey rounds. 


\section{Introduction}

The ECB decided to start conducting a survey of macroeconomic expectations in the euro area in early 1999. The survey is known as the Survey of Professional Forecasters (SPF) to reflect the fact that all of the survey participants are experts affiliated with financial or non-financial institutions based within the EU. The SPF questionnaire includes questions on expectations for HICP inflation, the real GDP growth rate and the unemployment rate in the euro area over different horizons, as well as questions seeking to quantify the uncertainty surrounding these variables.

The purpose of this paper is to describe the ECB's SPF in some detail so that anyone interested in using the results of the survey is aware of the main characteristics of the data. Section II considers the reasons for launching the SPF. Section III provides an overview of the survey, looking at the design and content of the SPF questionnaire, the composition of the panel of forecasters and the participation in the survey. The information provided in this section helps potential users to interpret the survey results. Section IV describes some salient features of the results collected in the first four years of the SPF and shows how these results can be used to infer information about private sector views on recent macroeconomic developments in the euro area. Section $V$ offers some concluding remarks. 


\section{The motivations for the ECB's Survey of Professional Forecasters}

The main reason for launching the SPF was to collect information about private sector macroeconomic forecasts for the euro area. Indeed, expectations about future economic developments are a very important piece of information for any economic agent. Whether it be in central banks, public institutions, private businesses or individual households, any economic decision is made taking into account expectations about future economic developments. Any central bank's decision on interest rates is underpinned by a rigorous assessment of the macroeconomic outlook. Managers' decisions to expand their businesses, change their prices or recruit more workers are based on the demand the managers expect for their products in the future. Individuals also make their consumption and savings decisions on the basis of their expectations about future developments. All economic decisions are therefore influenced to a large extent by our expectations about future economic developments.

In the specific case of monetary policy-making, central banks face substantial uncertainty regarding the impact of their monetary policy decisions on the economy in general and on price developments in particular. The presence of long and possibly variable time-lags in the transmission of monetary policy impulses to prices is well known to economists and policymakers and has prompted the design of forward-looking monetary strategies by all central banks, including the ECB. In this respect, the ECB's monetary policy strategy assigns an important role to monetary analysis in recognition of the fact that money growth and inflation are closely related in the medium to long term. Under the ECB's two-pillar approach, this assessment of monetary developments complements the ECB's regular monitoring of economic developments in the euro area, which covers a wide range of economic and financial indicators in order to form a broadly based assessment of the future risks to price stability.' Within this range of indicators of short-to-medium-term economic developments, private sector inflation expectations are a key piece of information because they can signal future risks to price stability or at least provide information about how economic agents gauge these risks. Information on market participants' views of future economic developments in the euro area, and in particular their inflation expectations, is therefore an important additional input into monetary policy decisions.

There are several alternative sources of information on private sector expectations of future price developments. One obvious strategy for gathering information on inflation expectations is to ask market participants about their outlook for price developments by means of surveys. An alternative way of gathering such information is to extract it from financial asset prices. The reason for this is that, given their forward-looking nature, asset prices should incorporate the inflation expectations of financial market participants. Unfortunately, a shortcoming of this approach is that certain critical assumptions are necessary to extract inflation expectations from asset prices. ${ }^{2}$ In this regard, an advantage of survey measures of inflation expectations is that the expectations are obtained directly from the survey participants. However, in the case of surveys, factors such as the characteristics of the panel of participants and the specific design of the questionnaire can also be crucial for the quality of the results. Given these considerations and the importance of inflation expectations for monetary policy, measures of inflation expectations extracted from financial asset prices and survey data on such expectations should be seen as complements rather than substitutes for each other when assessing private sector inflation expectations.

The ECB decided to launch its own survey of macroeconomic expectations with the aim of gathering information on private sector expectations as one of the wide range of

I For a recent description of the ECB's monetary policy strategy, see the article entitled "The outcome of the ECB's evaluation of its monetary policy strategy" in the June 2003 issue of the ECB's Monthly Bulletin.

2 For a fairly non-technical discussion, see the article entitled "The information content of interest rates and their derivatives for monetary policy" in the May 2000 issue of the ECB's Monthly Bulletin. 
indicators that the Governing Council of the ECB regularly monitors to assess macroeconomic developments in the euro area. In this context, the design of the survey took into account the need to provide the Governing Council with the most useful information on private sector expectations.

Several considerations were central in designing the questionnaire to meet the latter objective. First, it was considered important to gather quantitative estimates of private sector expectations. Second, information should be collected for several different horizons, and in particular at a relatively long horizon of five years. Third, it was also deemed desirable to gather quantitative information on the uncertainty surrounding private sector expectations, because it was considered that the forecasting of variables for a new macroeconomic area and with a new monetary regime could be particularly challenging. Finally, the collection of information on expectations not only about inflation but also real GDP growth and unemployment in the euro area was also considered useful for an overall macroeconomic assessment.

When considering the conduct of a survey to collect such information, a problem arises because forecasting macroeconomic variables is not an easy task, and providing accurate quantitative information on the uncertainty surrounding the point estimates is even more difficult. In this regard, it was fundamental to ensure that macroeconomic forecasting was part of the regular duties of the survey participants to guarantee the quality of the results. Only a survey of professional forecasters could provide accurate quantitative responses to questions about expected inflation, especially for relatively long horizons, and a measure of the uncertainty surrounding them. In this sense, it was thought that the SPF results on inflation expectations could complement the results of existing surveys for the euro area in 1999, such as the European Commission's harmonised survey of the price expectations of individual households and the survey of professional experts conducted by the London-based institute Consensus Economics. $^{3}$ For a survey of the general population to yield meaningful information, it must be confined to questions that the average consumer can reasonably be expected to answer. Most households are able to respond in a meaningful manner whether they expect prices over the next 12 months to rise more or less rapidly than over the past 12 months. It is, however, less likely that the average consumer can provide a thorough quantitative assessment of the risks surrounding future price developments, as needed for example to assign accurate quantitative probabilities to the alternatives of prices rising $0.5 \%$ faster or $0.5 \%$ slower. A survey of professional forecasters also has other advantages. For example, the information content of survey data on inflation expectations is sometimes questioned because these expectations might not be those on which economic decisions are based or those in which economic agents truly believe. These arguments are, however, unlikely to apply in the case of people who make macroeconomic forecasts as part of their regular duties. In addition, other available surveys of professional forecasters, such as that of Consensus Economics and the more recently launched Euro Zone Barometer, do not ask participants to assign probabilities to different inflation outcomes on a regular basis. While point estimates of expected inflation are useful in assessing developments in the credibility of monetary policy, the degree of uncertainty associated with these estimates is also a very valuable source of information for monetary policy-makers, and in general for any decisionmaker.

In addition to the expertise of the panel participants, other characteristics of the panel such as its size and composition are important to guarantee the representativeness of the results from a euro area perspective. The panel of participants was assembled with the assistance of the national central banks (NCBs) of the EU, which were invited to nominate institutions and forecasters from their countries.

3 A description of the main characteristics of these and other similar surveys can be found in Annex II. 


\section{An overview of the ECB's Survey of Professional Forecasters}

\section{The SPF questionnaire ${ }^{4}$}

The SPF questionnaire asks for HICP inflation expectations, the expected rate of real GDP growth and the expected unemployment rate in the euro area over different horizons, together with a quantitative measure of the uncertainty surrounding these variables. Aggregate results for each variable and horizon are compiled by the ECB on the basis of the individual replies. The frequency and timing of the survey, the variables for which expectations are requested, the forecast horizons and other important features of the SPF questionnaire are described in detail below.

\section{Frequency of the survey and availability of the results}

The ECB's SPF is conducted four times per year, with the survey rounds currently taking place in the first month of each quarter, i.e. in January, April, July and October. ${ }^{5}$ The questionnaire is sent out to the participants immediately after the HICP data for the last month of the previous quarter are released by Eurostat. $^{6}$ These releases usually take place by the third week of the month and therefore the survey is usually conducted in the second half of the first month of each quarter. Soon after the survey is completed, a brief summary of the results of the survey round, together with information from other sources on private sector expectations, is published in a box in the ECB's Monthly Bulletin (i.e. in the February, May, August and November issues). From October 2003, the complete set of aggregate results for the most recent survey round, as well as historical data, will be freely available to all interested parties on the webpages dedicated to the SPF (http://www.ecb.int/stats/spf).

\section{Economic variables forecast}

The SPF is mainly aimed at collecting information on inflation expectations. Given that the statutory mandate of the ECB and the quantitative definition of price stability adopted by the Governing Council of the ECB are based on the HICP, expectations are requested for the annual rate of growth in the HICP. It is also important to bear in mind that, despite the broad composition of the panel of participants in terms of nationality, inflation expectations are requested for the euro areawide HICP, and not for the national HICP according to each forecaster's nationality. The aggregate results of the survey therefore reflect the average results across the panel of forecasters in contrast to a (weighted) average of forecasts of national HICP inflation rates.

For inflation expectations to convey more useful information about private sector views on macroeconomic developments, it is important to place them in the context of the prospects for the overall economy. This is why survey participants are asked to provide, together with their expectations for annual HICP inflation rates, their expectations for the year-on-year percentage change in euro area real GDP and for the euro area unemployment rate for the same horizons as for the HICP inflation forecasts. For a statistical definition of the variables requested, see the box below.

For the sake of clarity and brevity, the main characteristics of the survey questionnaire are described below with reference to the information regarding inflation expectations. Whenever differences for other variables are relevant, additional remarks are included.

4 A copy of the questionnaire used in a recent survey round is also available on the webpages dedicated to the SPF (http://www.ecb.int/stats/spf).

5 Data users should take into account the fact that from 1999 until 2001 Q3, the ECB's SPF was conducted in the middle month of the quarter, i.e. February, May, August and November.

6 This should allow the forecasts supplied by participants to be based on the information available up to the moment the survey is conducted and to which the "rolling horizons" refer (see the description of the forecast horizons later in this section). Given the deadlines for the collection of the replies, the publication of the "flash estimates" based on limited country coverage that were introduced by Eurostat from November 200I for the HICP and from May 2003 for GDP should not affect this assumption. 


\section{B॰x}

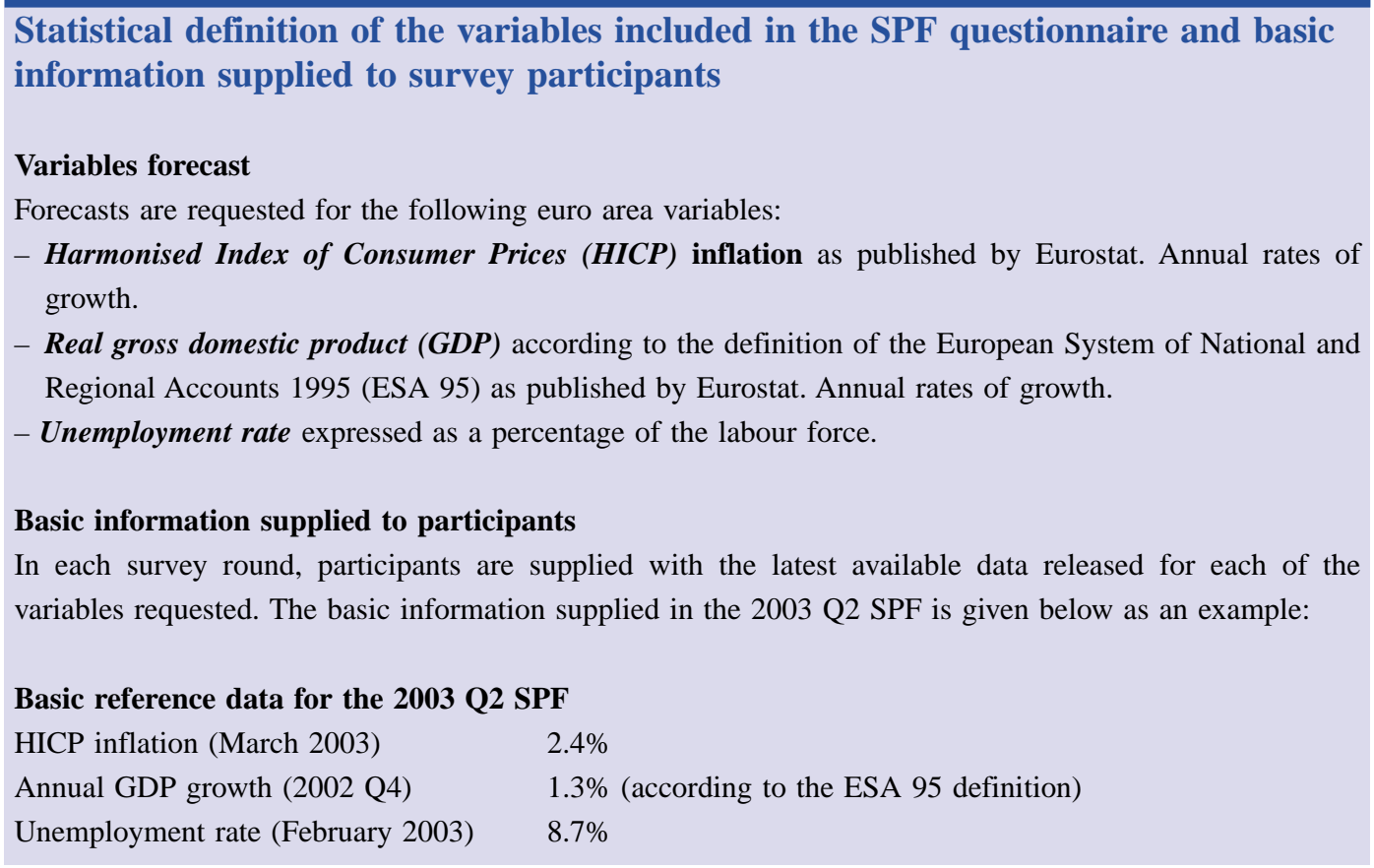

\section{Forecast horizons}

The SPF questionnaire asks for expectations at three different sets of horizons. First, in the survey rounds in the first and second quarters of the year, forecasters are asked to provide expectations for the current and the next calendar years, while in the survey rounds in the third and fourth quarters they are also asked to give their expectations for the nextbut-one calendar year. For example, in the 2003 Q2 SPF, forecasters were asked to provide expectations for average inflation, real GDP growth and the unemployment rate in the current year and in the next calendar year. It should be noted that this means that expectations for a given calendar year are requested in several survey rounds in a row, which allows changes over time in the expected inflation rate among the forecasters to be detected (see Section IV for an illustration).

Second, forecasters are also asked to provide their expectations for two specific months (quarters for the real GDP growth rate) that are set one and two years ahead of the latest available data for the respective variables. It is important to note that, although the survey is conducted at a quarterly frequency, two of the variables for which forecasts are requested - namely the HICP inflation rate and the unemployment rate - are available at a monthly frequency. For this reason, in the survey the forecasts of these variables for the "rolling horizons" are requested for specific months. These specific months (quarters for the real GDP growth rate) are "rolling" over time as new information becomes available. For example, in the first survey in the first quarter of 1999 (sent out after the official release of the December 1998 figure for HICP inflation), the questionnaire asked for the expected year-onyear inflation rate in December 1999 and December 2000. In the second survey, the 1999 Q2 SPF (sent out after the release of the March 1999 HICP figure), the questionnaire asked for the expected year-on-year inflation rate in March 2000 and March 200I, and so on.

Finally, forecasters are asked to provide expectations for a longer horizon set five years ahead. Here the aim is to get an idea of the level of longer-term inflation expectations, which are fundamentally related to the credibility of the ECB's commitment to price stability, as well as of private sector expectations for euro area potential growth. 
In the first two years of the survey, the expectations for these longer-term horizons were only requested in the survey rounds conducted in the first quarter of the year, i.e. in the 1999 QI SPF and the 2000 QI SPF. However, since 200I they have been requested in all survey rounds.

\section{Uncertainty surrounding expectations for each horizon}

Although the point estimates (i.e. the most likely value for the annual inflation rate at each horizon) are a useful piece of information about private sector expectations, it is also important to gather some information about the uncertainty surrounding these point estimates. In principle, a possible measure of the uncertainty of the expectations can be inferred by looking at the extent to which the levels reported by the different forecasters differ. In this sense, the level of uncertainty in private sector expectations would be given by the differences among the survey participants. ${ }^{7}$

However, it is also of interest to collect quantitative information about how uncertain each forecaster is about his/her forecast. To this end, for each of the three variables and for each horizon, the forecasters are asked to report, together with their preferred value, the degree of uncertainty surrounding their expectations by allocating subjective probabilities to ranges of possible outcomes with a width of 0.5 percentage point. For example, in the 2003 Q2 SPF, forecasters were asked to assign probability to the actual average inflation rate for 2003 falling between $0.0 \%$ and $0.4 \%, 0.5 \%$ and $0.9 \%, 1.0 \%$ and $1.4 \%$, and so on. Although the number of such intervals (or "bins") is obviously limited in the questionnaire, the lower-end and the upperend intervals are left open for the forecaster to provide the cumulative probability of the actual value being lower or higher than a specified value without any further reference to how much lower or higher (e.g. for lower values, $\leq 0 \%$, and for higher values, $\geq 3.5 \%)$. ${ }^{8}$ This formulation allows forecasters to provide a well-defined probability distribution for all the possible outcomes that reflects quantitatively how uncertain they are about their forecast.

These assigned probabilities reflect the forecaster's assessment of the risk that the actual outcome will fall outside the range considered most likely at the time the forecast is made. Although the aggregate probability distribution constructed from these individual assessments may encompass many different assumptions and macroeconomic scenarios, it helps to assess how survey participants, on average, gauge the risk of the actual outcome being above or below the most likely range.

\section{Additional features of the SPF questionnaire}

Another important feature of the SPF is that survey participants are not given a common set of assumptions upon which to base their forecasts. The only information supplied to them is the latest published data on the variables for which their expectations are requested (see Box I for an example). The aggregate results are therefore likely to reflect a relatively heterogeneous set of subjective views and assumptions.

The SPF questionnaire contains a noncompulsory section that requests information on the factors underlying each respondent's expectations. In particular, the forecaster's assumptions for the Eurosystem's main refinancing rate, oil prices and the USD-EUR exchange rate in each of the next five quarters are explicitly requested, and forecasters are encouraged to add as much information as they wish about these factors or other factors that they consider important in each survey round.

7 For a recent discussion of alternative measures of uncertainty surrounding survey data, see for example Giordani and Soderlind (2003).

8 Note, however, that the number of intervals included in the questionnaire is not fixed; it is increased (or reduced) as needed to guarantee that the open intervals remain "redundant" in the sense of not having any significant proportion of the probability assigned to them on a regular basis. 
Occasionally, the questionnaire also asks participants specific questions about issues of special relevance at the time of conducting the survey. For example, the 200I Q4 SPF was conducted in the second half of October, roughly a month after the events of September II. These events obviously had a substantial impact on the economic outlook and, for that particular survey round, the rather limited set of post-September II data forced forecasters to base their forecasts to a certain extent on purely judgemental scenarios. In this context, forecasters were invited to provide additional details of their assessment of the potential consequences of those events for the euro area variables in a special section after the regular sections of the questionnaire.

\section{The panel of forecasters}

The ECB's SPF questionnaire is regularly submitted to nearly 90 forecasters, quite a large number compared with the number of participants in other similar surveys. ${ }^{9}$ Moreover, SPF participants form a rather heterogeneous group, as can be seen from the information reported below. Since the composition of the panel is an important factor for assessing the representativeness of the expectations collected, this section describes the panel of participants in further detail.

First of all, it should be recalled that the survey is known as the Survey of Professional Forecasters to reflect the fact that all of the participants are experts affiliated with financial or non-financial institutions based within the EU. As already mentioned, the desire to collect fairly precise information about private sector expectations and to carry out a thorough quantitative assessment of the uncertainty surrounding the forecasts at several different horizons led to the decision to conduct the survey on people who produce forecasts as part of their regular duties.

The EU NCBs played a key role in assembling the panel of forecasters. Although no minimum number of forecasters was required from any particular country, it was judged important in view of the specific nature of the euro area to attain a balanced representation of nationalities. Another important feature of the panel is that it was constructed from the EU as a whole and not just from euro area countries, although the questionnaire only requests expectations for the euro area. Chart I below illustrates the composition of the panel according to the country in which the forecaster's institution is based.

9 See Annex II for a description of similar surveys.

Chart I

Number of participants by nationality

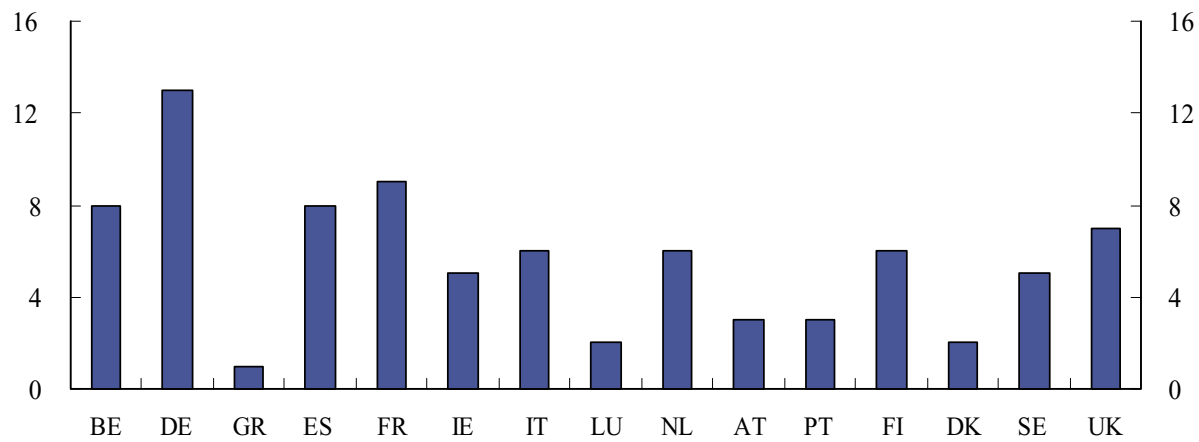


An important feature of the survey is the anonymity of the participants. ${ }^{10}$ This guaranteed anonymity should encourage participants to submit their forecasts and the uncertainty surrounding them as judged at the time of the survey without any concern about forecast errors. This may have been particularly important in the early stages of the survey when it is possible that many of the participants had econometric models for the euro area that were still in a preliminary stage of development.
An additional key feature of the participants is the sector to which their institution belongs. This information is shown in Chart 2 below.

As can be seen, there is a fairly even balance between panel participants from the financial sector and those from outside the financial sector.

10 The ECB does not plan to disclose the names of the forecasters, at least for the time being.

\section{Chart 2}

Number of participants by sector

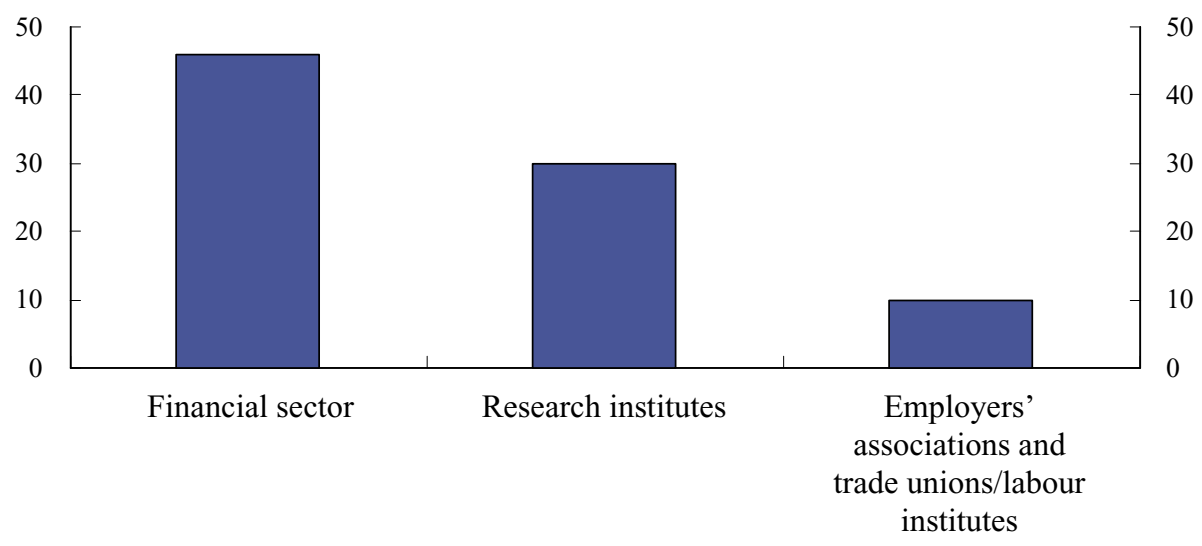

\section{Participation}

A crucial feature of any survey is the response rate over time. In particular, a stable response rate helps to ensure that the measured expectations are truly representative of the selected panel. This section reports the response rates obtained so far, both in terms of the number of replies received per survey round and the individual participation of each forecaster.

Over the first 18 rounds, the average number of replies was 58 , which is relatively high

\section{Chart 3}

Number of replies received per survey round

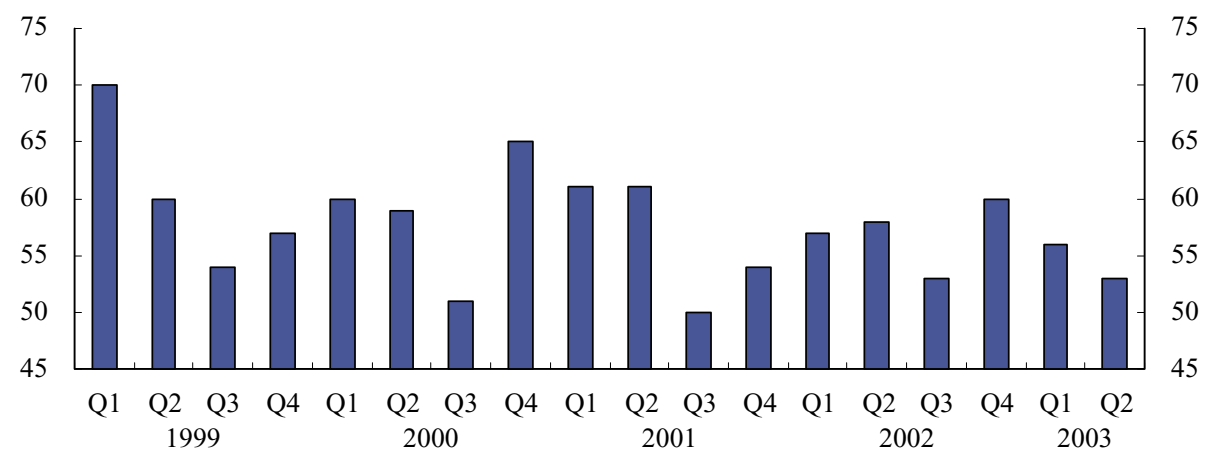


compared with similar surveys. However, participation has fluctuated somewhat in these 18 rounds and tends to show a negative seasonal pattern in the Q3 round, where the average number of replies has been 52 . All in all, the participation in the survey so far can be considered satisfactory.

In addition to the aggregate response rate, it is important to bear in mind the individual participant's response rate in order to verify that it is not compositional changes but revisions in the assessment of the economic situation that drive changes in expectations from one survey round to the next. In this regard, and although some of the participants have left the panel (e.g. as a result of departures from the institutions, mergers between institutions, etc.), there are a substantial number of SPF participants (around 40 ) with a participation rate of above $80 \%$, and the number of participants that has participated in at least half of the surveys conducted in the period from $1999 \mathrm{QI}$ to 2003 Q2 is above 60. 


\section{An overview of the results | 999-2003}

This section presents a selection of the SPF results up to the 2003 Q2 SPF. Here again the focus will be on inflation expectations, but some detailed information on the other two

\section{Inflation expectations}

\section{Average inflation expectations for full calendar years}

Inflation expectations for a given calendar year are requested in several consecutive survey rounds. This helps to assess how expectations have changed over time as the end of the year in question approaches. For example, Chart 4 depicts the expected average inflation for the calendar year 2003 in all the survey rounds in which expectations for such a horizon have been requested so far.

The chart shows that expectations have remained very stable, hovering around $1.8 \%$. However, in the 2003 Q2 survey round, participants revised their expectations upwards by almost 0.2 percentage point to an average of $2.0 \%$ for the year as a whole. According to the comments of the survey participants, this latest upward revision seems to be related to oil price developments in the first months of 2003 as a result of geopolitical tensions and the eventual military conflict in Iraq. Oil price developments had already been mentioned as an upward risk in earlier survey rounds. Although participants expected the impact of oil price developments to ease variables for which expectations are requested - namely real GDP growth and the unemployment rate - is also given.

substantially over 2003, and indeed expectations for the rest of the horizons were not revised upwards, inflation outcomes in the first months of the year obviously led to higher expected average inflation for the year as a whole.

\section{Probability distributions for expected inflation}

The SPF questionnaire asks for a quantitative assessment of the uncertainty surrounding participants' expectations for each variable and horizon. More specifically, it asks survey participants to assign a probability to actual outcomes falling into specific intervals (for example, some of the intervals for inflation expectations are shown on the horizontal axis in Chart 5). The assigned probabilities reflect the forecaster's assessment of the risk of the actual outcome being different from the value considered most likely at the time the forecast is made. Although the aggregate probability distribution constructed from these subjective assessments may encompass many different macroeconomic scenarios, it helps to assess how survey participants, on average, gauge the

\section{Chart 4}

\section{Expected average inflation for 2003}

(percentages)

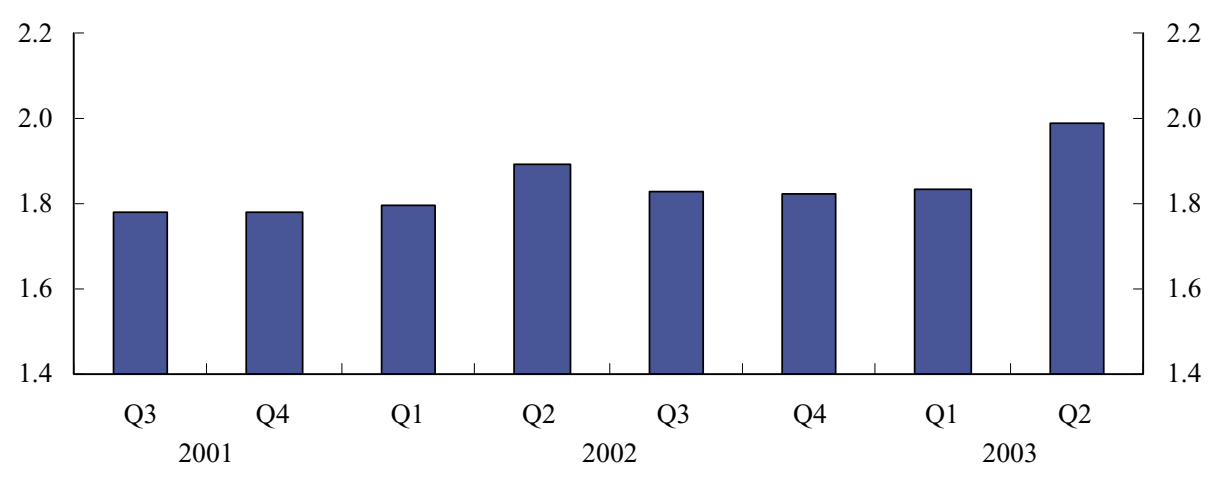


(percentages)

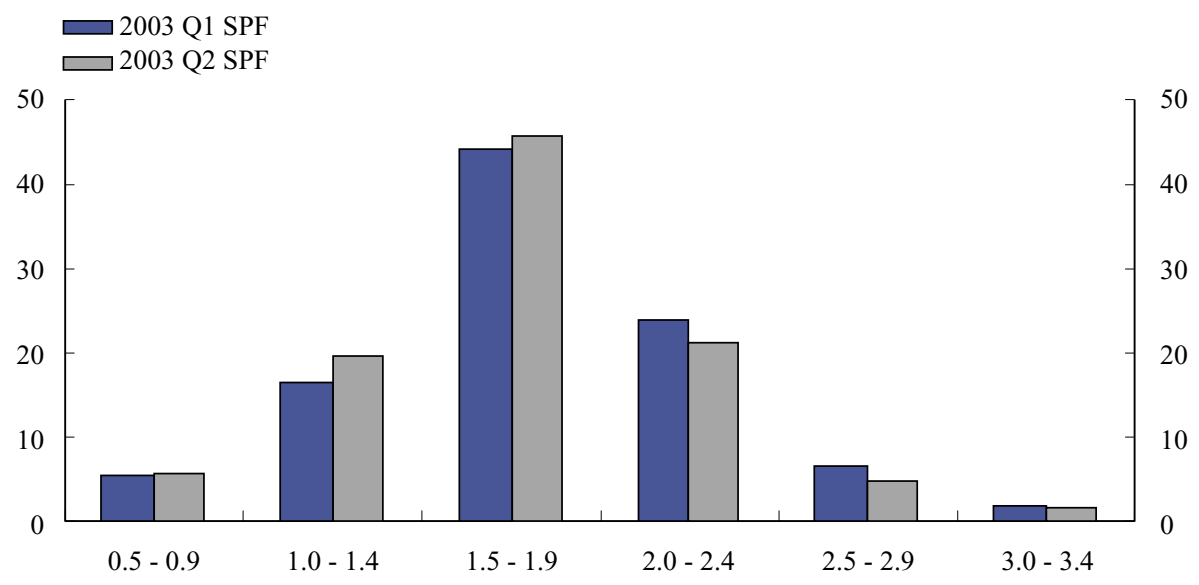

risk of the actual outcome being above or below the most likely range.

Chart 5 shows the aggregate probability distributions for the annual HICP inflation rates expected on average for the next calendar year, 2004, in the first two survey rounds of 2003. In the 2003 Q2 SPF, as expected, the highest probability (around 45\%) is assigned to the range of values around the point estimate for this horizon, $1.7 \%$, i.e. to the $1.5-1.9 \%$ interval. In this particular case, the distribution is fairly well balanced around this central range of $1.5-1.9 \%$. This suggests that survey participants perceive an equal risk that actual average inflation in 2004 will turn out to be above or below the most likely range of I.5-1.9\% (around $27 \%$ on either side).

The blue bars in Chart 5 represent the probability distribution for the expected annual HICP inflation rate in 2004 as reported in the 2003 QI SPF. In this case, survey participants also expect inflation to fall within the $1.5-1.9 \%$ range, most likely at $1.8 \%$. However, in contrast to the probability distribution from the 2003 Q2 survey round, the distribution from the 2003 QI round suggests that risks for inflation in 2004 were seen as slightly more asymmetrical since the probability distribution is skewed to the right of the central interval. This indicates that survey participants considered that there was a higher risk of inflation turning out to be above the $1.5-1.9 \%$ range in 2004 than of it ending up below 1.5\%. This is reflected in a cumulative probability of around 33\% assigned to outcomes above the most likely I.5-I.9\% range and only $23 \%$ to outcomes below this range. This change in the overall assessment of the balance of risks with regard to expected inflation between these two survey rounds seems to be mostly related to survey participants' expectations of a worsening outlook for economic activity in the euro area towards the end of 2003 and in 2004 (see also Chart 9 on growth prospects for 2003).

\section{Inflation expectations over rolling horizons}

Expectations over the rolling horizons that are set 12 months and 24 months ahead of the latest official data release at the time of the survey help to evaluate participants' assessment of the dynamics of inflation, which is more difficult to disentangle from the averages for the calendar years.

Chart 6 presents the mean values for the expectations collected one year ahead, together with an indicator of the uncertainty surrounding them. As indicated in the legend, the uncertainty bands are constructed by adding to and subtracting from the mean 


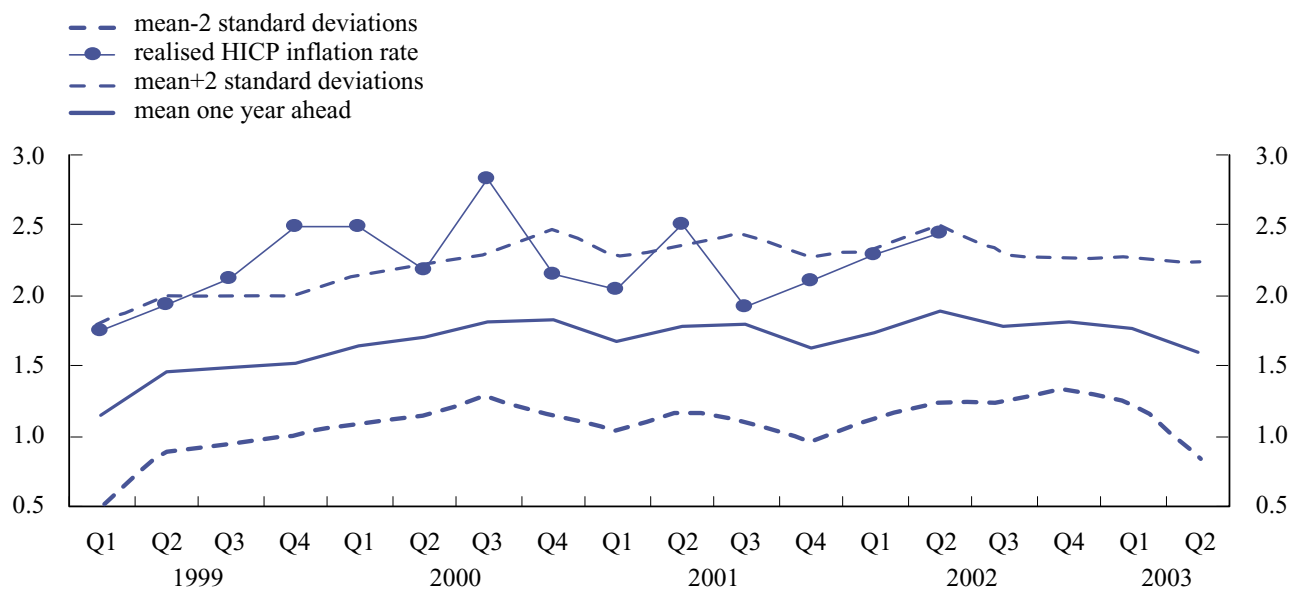

values of the point estimates twice the standard deviation among the point estimates of the forecasters." The realised inflation rates for the horizon requested in each survey are also depicted to allow a comparison with these mean forecasts.

Mean inflation expectations one year ahead have remained below the $2 \%$ threshold over these four years, as have the two-year-ahead expectations (not shown). However, the most striking feature of the chart is the fact that the realised values have been systematically above the mean expected value, which indicates that a large number of participants has expected inflation to be lower than it turned out to be one year later. It is also worth noting that realised inflation has nonetheless been broadly within the uncertainty bands around the mean expected value, which also highlights the potential usefulness of taking into account measures of the uncertainty surrounding any point forecast.

A potential explanation for this most striking feature is that some of the shocks affecting euro area inflation in the last four years were not foreseen by most of the survey participants. This is understandable given the range of shocks hitting euro area inflation over that period: oil price increases, food price shocks and euro exchange rate shocks. ${ }^{12}$ Even if the direction of the effects of such a clustering of shocks on euro area inflation could have been anticipated, the persistence of the effects was probably much more difficult to gauge. This seems to be a fundamental part of the explanation for the evidence shown in Chart 6. Indeed, the hypothesis that most survey participants appear to have considered the shocks to be much more short-lasting than they turned out to be is supported by the fact that survey participants did not revise their one-year-ahead estimates substantially in subsequent survey rounds even though the actual values of inflation were well above their previous estimates.

\section{Indicators of long-term inflation expectations}

Economic theory suggests that the credibility of a central bank can be tentatively assessed by the extent to which long-term inflation expectations are consistent with the monetary policy objective. In the case of the ECB this objective is clearly the maintenance of price

II For a recent discussion of this and alternative measures of uncertainty in survey data, see Giordani and Soderlind (2003) and the references therein.

12 For further information, see the box entitled "The clustering of shocks to HICP inflation since the start of Stage Three of EMU', ECB's Monthly Bulletin, June 2002, p. 34. 


\section{Indicators of long-term inflation expectations}

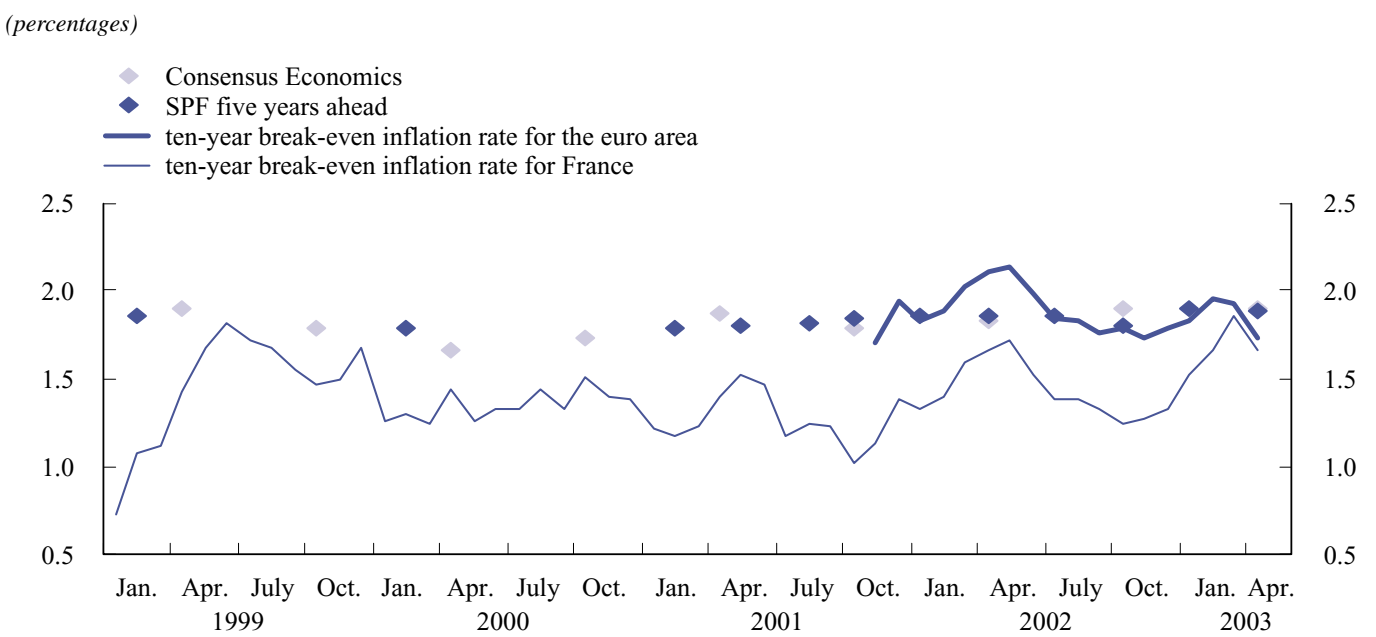

stability, which has been defined in quantitative terms as a rate of HICP inflation below but close to $2 \%$ over the medium term. SPF inflation expectations collected at a fairly longterm horizon of five years can help to assess the extent to which private sector inflation expectations for the euro area are consistent with the ECB's definition of price stability. Since the beginning of the survey in 1999, such expectations have been within a narrow range between $1.8 \%$ and $1.9 \%$, and therefore systematically below $2 \%$, as can be seen in Chart 7. Results from other surveys of inflation expectations for the euro area, namely Consensus Economics and the Euro Zone Barometer (not shown), broadly convey the same message.

These survey measures of expected inflation are also broadly consistent with the measure of inflation expectations extracted from the long-term bonds indexed to the euro area HICP excluding tobacco issued by the French Treasury. A measure of long-term inflation expectations can be derived from index-linked bonds as the difference between the nominal yield on a standard bond and the real yield on an inflation-indexed bond issued by the same issuer and with similar maturities. This measure is commonly known as the breakeven inflation rate because it provides an estimate of the level of expected inflation at which, under certain assumptions, an investor would be indifferent about holding either type of bond. This break-even inflation rate extracted from this type of bond has also remained below $2 \%$ for most of the time since such bonds were first issued in November 200I. It is important to bear in mind, however, that break-even inflation rates are not a direct measure of market participants' inflation expectations since they may be influenced by risk, maturity and liquidity premia. For example, the break-even inflation rate is likely to incorporate a positive premium related to inflation uncertainty and a negative premium related to the higher liquidity of the nominal bonds used to calculate the break-even inflation rate. ${ }^{13}$ Indeed, these premia seem to have played a significant role in shaping developments in break-even inflation rates in 2002 and 2003.

\section{A comparison with consumers' inflation expectations}

An alternative source of inflation expectations for the euro area is the monthly survey of consumer expectations conducted on behalf of the European Commission (EC). ${ }^{14}$ As

13 For a thorough description of the nature of break-even inflation rates, see the box entitled "Deriving long-term euro area inflation expectations from index-linked bonds issued by the French Treasury" in the February 2002 issue of the ECB's Monthly Bulletin.

14 Some basic information on the EC Consumer Surveys can be found in Annex II. For a thorough description, see European Economy (1997), No. 6. 
mentioned before, the ECB's Survey of Professional Forecasters differs in many respects from the EC Consumer Surveys, but it is nevertheless interesting to look at how the expectations of professional forecasters and those of consumers compare with each other. Chart 8 depicts the mean average inflation expected one year ahead, realised inflation and expectations from the EC Consumer Surveys. In this survey participants are asked how they assess developments in prices in the next 12 months compared with the current situation, and the survey results are reported in qualitative terms, i.e. as the "balance statistic". Specifically, survey participants are requested to choose between five possible answers for the expected developments in prices: (1) increase more rapidly, (2) increase at the same rate, (3) increase at a slower rate, (4) stay about the same, or (5) fall. The balance statistic is computed on the basis of the proportions of respondents opting for the different response categories. ${ }^{15}$ To facilitate the comparison with the SPF results and actual inflation rates, a quantitative estimate ${ }^{16}$ of the expectations from the EC Consumer Survey is also presented.
The SPF results and the quantified measure of consumers' expectations moved very closely together in 1999 and 2000, with both tending to underestimate the actual inflation outcome. However, the differences between the two sources of expectations became larger from 200I, when the mean SPF forecast one year ahead continued with a tendency to underestimate realised inflation, while the quantified measure of consumers' expectations tended to overestimate it. This may suggest that consumers tended to overestimate the length of the shocks to inflation in this later period, while professional forecasters may have underestimated it. ${ }^{17}$

15 The balance statistic is calculated as $\left(S_{1}+1 / 2 S_{2}\right)-\left(1 / 2 S_{4}+S_{5}\right)$ where $S_{i}(i=I, 2,3,4$ and 5) denotes the sample proportions opting for each of the five response categories.

16 For a description of the method employed and potential alternatives, see Forsells and Kenny (2002) and the references therein. See also Deutsche Bundesbank (200I).

17 In the case of the quantified consumer inflation expectations, the calculation shown here is likely to be influenced by the high perceptions of inflation also reported in the survey. For further information, see the references quoted in the previous footnote.

\section{Chart 8}

A comparison with inflation expectations from the EC Consumer Surveys: balance statistic (right-hand scale) and quantified EC survey results (left-hand scale)

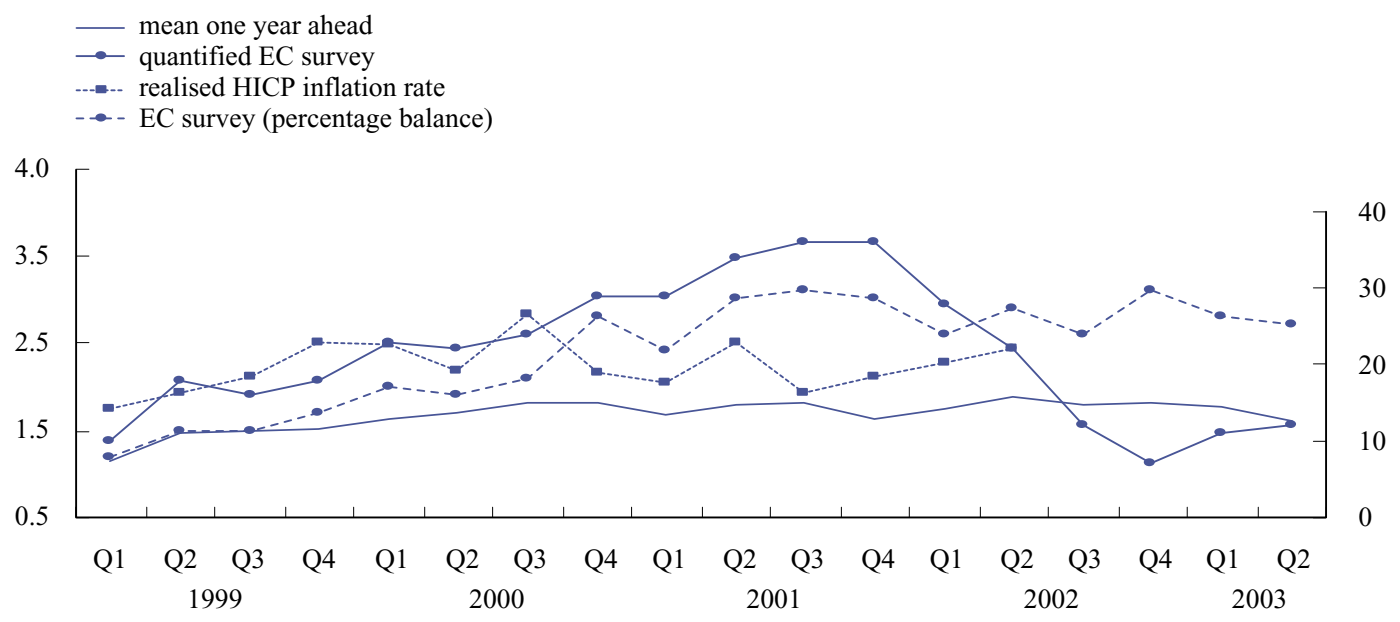




\section{Growth expectations}

As with the inflation forecasts, the fact that the average growth rate for a particular year is requested in several survey rounds allows for a comparison of the changes in the forecasts over time. Chart 9 shows the mean forecast for the average real GDP growth rate expected for 2003.

\section{Chart 9}

Average real GDP growth rate expected for 2003

(percentages)

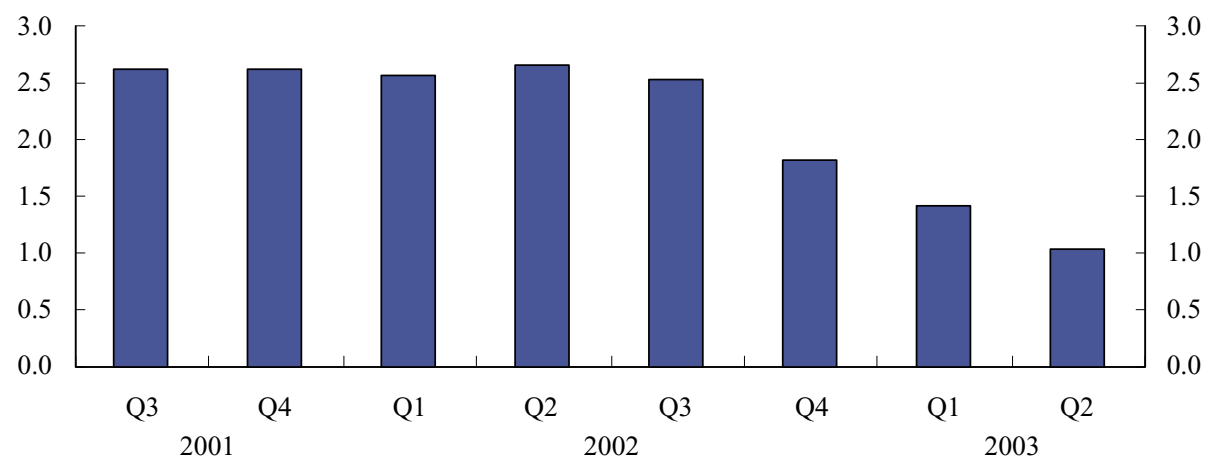

The mean forecast for real GDP growth in 2003 remained slightly above $2.5 \%$ in the first five survey rounds in which it was requested. However, in the subsequent three survey rounds it was substantially revised downwards, to around $1.0 \%$ in the 2003 Q2 SPF conducted in the second half of April, reflecting the growing pessimism about the economic outlook in the euro area. As can be seen in Chart 10, the downward revision in the point estimates for growth in 2003 is also reflected in the probability distributions in the last two survey rounds, where the probability assigned to outcomes below $1 \%$ increased following the revision from $1.4 \%$ to $1.0 \%$ in the mean point estimate.

In terms of predictive content, forecasting real GDP growth seems to have been more problematic than forecasting the inflation rate over the first four years of the survey. In a similar fashion to the analysis provided earlier for inflation expectations, Chart II depicts the mean value of the real GDP growth forecasts one year ahead together with uncertainty bands and realised values for the horizons for

\section{Chart 10}

Probability distribution for average real GDP growth in 2003

(percentages)

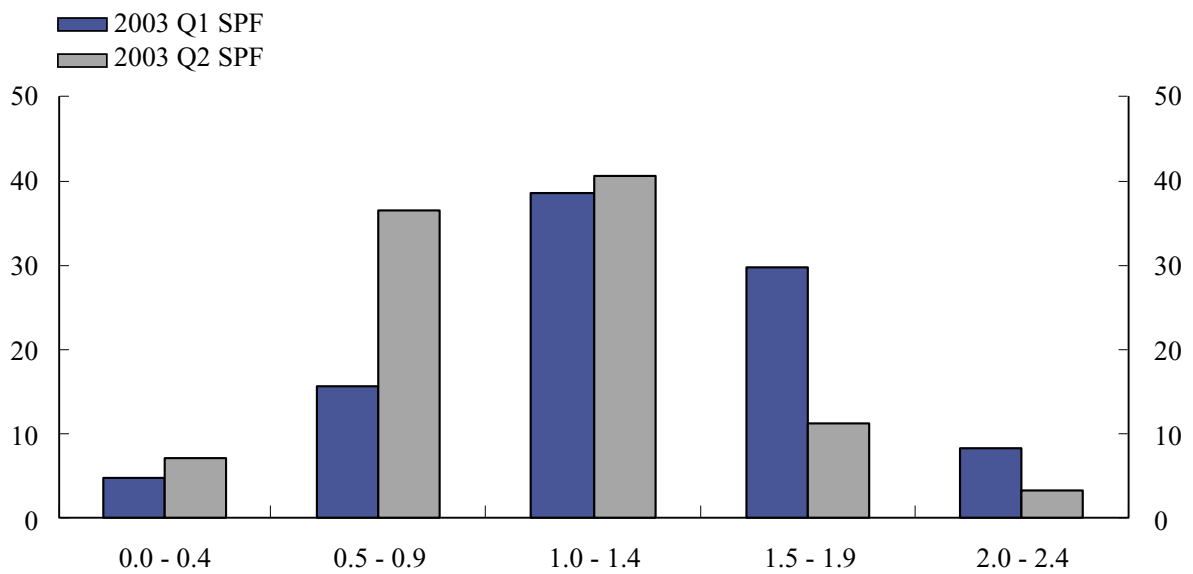




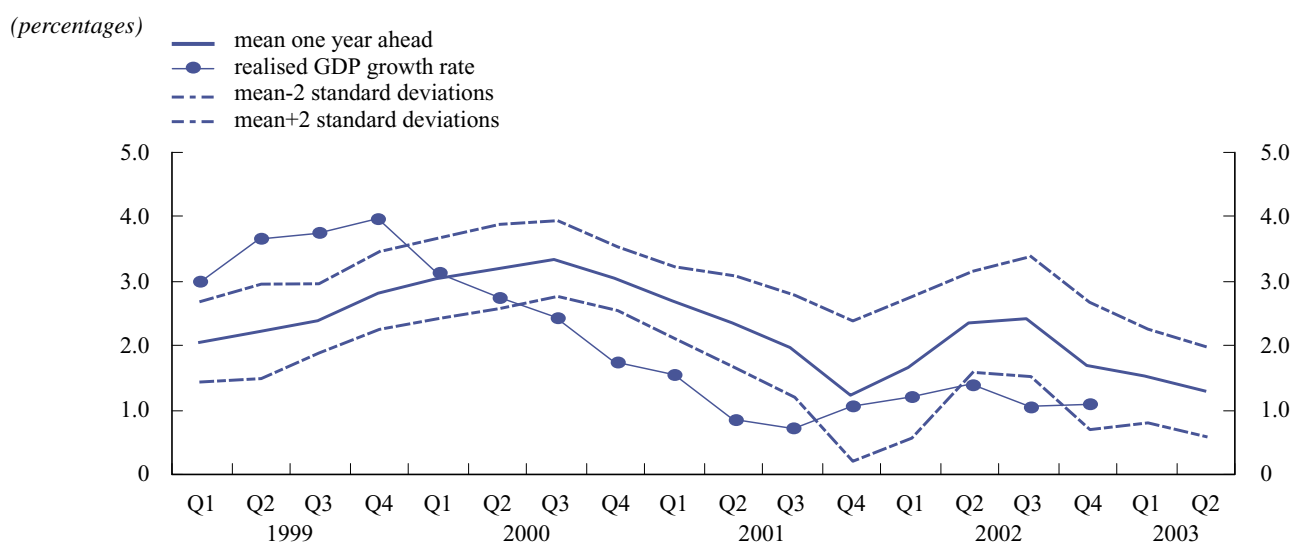

which forecasts were requested in each survey round.

The realised values have fallen outside the uncertainty bands on a large number of occasions. For example, the growth rate was underestimated between 1999 Q3 and 2000 $\mathrm{Q} 3$, and the subsequent moderation in the rate of growth also appears to have been underestimated at least until 200I Q4. These forecast errors are possibly related to the obvious difficulties experienced in forecasting economic activity for the euro area as a whole for the first time over a business cycle. ${ }^{18}$ From then onwards, expectations may reflect the fact that forecasters were incorporating into the reported forecast an economic recovery that was systematically delayed over time, as indicated in the forecasters' assessments in the questionnaires.

Longer-term growth forecasts can be interpreted as an estimate of potential growth in the euro area. Some movement in the long-term growth prospects in the course of the business cycle is to a certain extent normal in survey data. For example, these prospects would normally rise in an economic upturn

18 Before drawing conclusions about the forecasting performance of the survey participants, it has to be borne in mind that the realised values depicted in Chart II include data revisions, which could partly explain the forecast errors. The purpose of this graphical analysis is mainly descriptive. A thorough analysis of forecasting performance using the SPF dataset is beyond the scope of this paper and is left for further work.

\section{Chart 12}

\section{Long-term growth prospects}

(percentages)

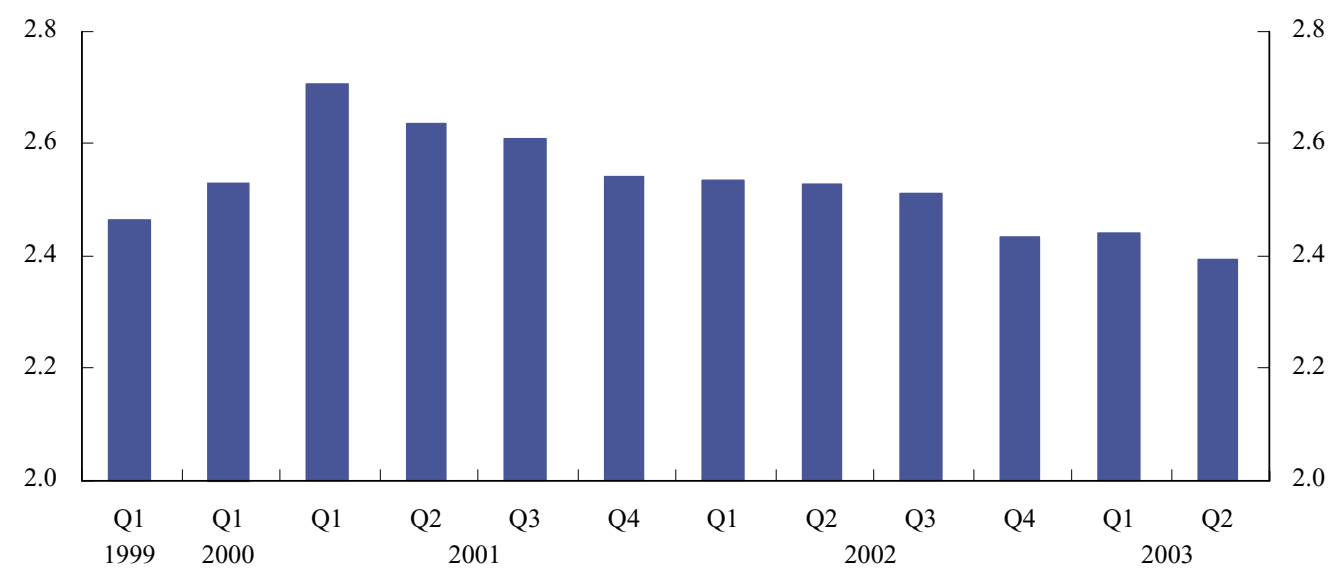


and fall in a downturn. However, in the absence of clear evidence of structural change, long-term growth forecasts tend to remain unchanged and temporary deviations are typically due to unsustainable changes in the rates of growth of labour, capital or total factor productivity. For instance, the strong economic upturn at the end of the 1990s gave rise to expectations of a "New Economy" and the possibility of permanently higher levels of growth, in particular in the United States, but perhaps also in the euro area, albeit to a much lesser extent.

Chart 12 shows the mean long-term growth forecasts for the euro area since 1999. Following the economic slowdown in the past two years, the prospect of sustained higher

\section{Unemployment expectations}

The unemployment forecasts collected over these years have suggested a clear downward trend in the unemployment rate in the euro area when the results for the different horizons requested in each survey round are compared. However, in line with the cyclical position of the euro area economy, the slowdown in economic activity has led to a series of upward revisions in the unemployment forecasts over 2003. These upward revisions have also translated into higher expected levels for the unemployment rate over the longer term, although the growth in the euro area now seems to have largely disappeared. Nevertheless, the movement between 1999 and 2002 might also signal expectations of a more fundamental change in economic growth, which did not materialise. The long-term forecast reached a peak in the first quarter of $200 \mathrm{I}$, at around $2.7 \%$. After that, the forecast came down gradually, although it still remains close to the upper end of the range assumed for trend potential growth in the euro area, at slightly below $2.4 \%$. However, the downward revisions to euro area long-term growth forecasts are likely to reflect factors other than vanishing optimism about a New Economy, such as an apparent lack of structural reform in product and labour markets.

unemployment rate is expected to continue on a downward trend.

Survey participants have, however, repeatedly mentioned that further structural reforms need to be implemented, especially in some countries, to allow the euro area unemployment rate to be further reduced in the years to come.

According to the results for the one-yearahead expectations for the unemployment rate, survey participants seem to have fairly

\section{Chart I 3}

Unemployment rate forecasts one, two and five years ahead

(percentages; all survey rounds from 1999 Q1 to 2003 Q2)

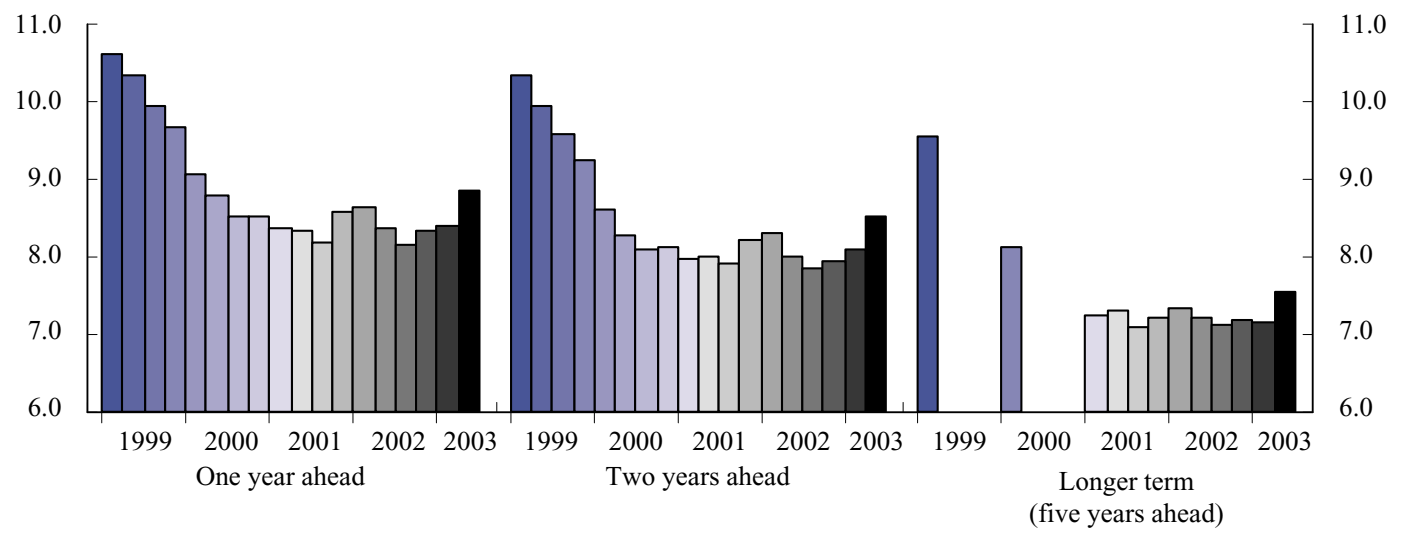




\section{Chart 14}

One-year-ahead expectations for the unemployment rate, uncertainty bands and realised values

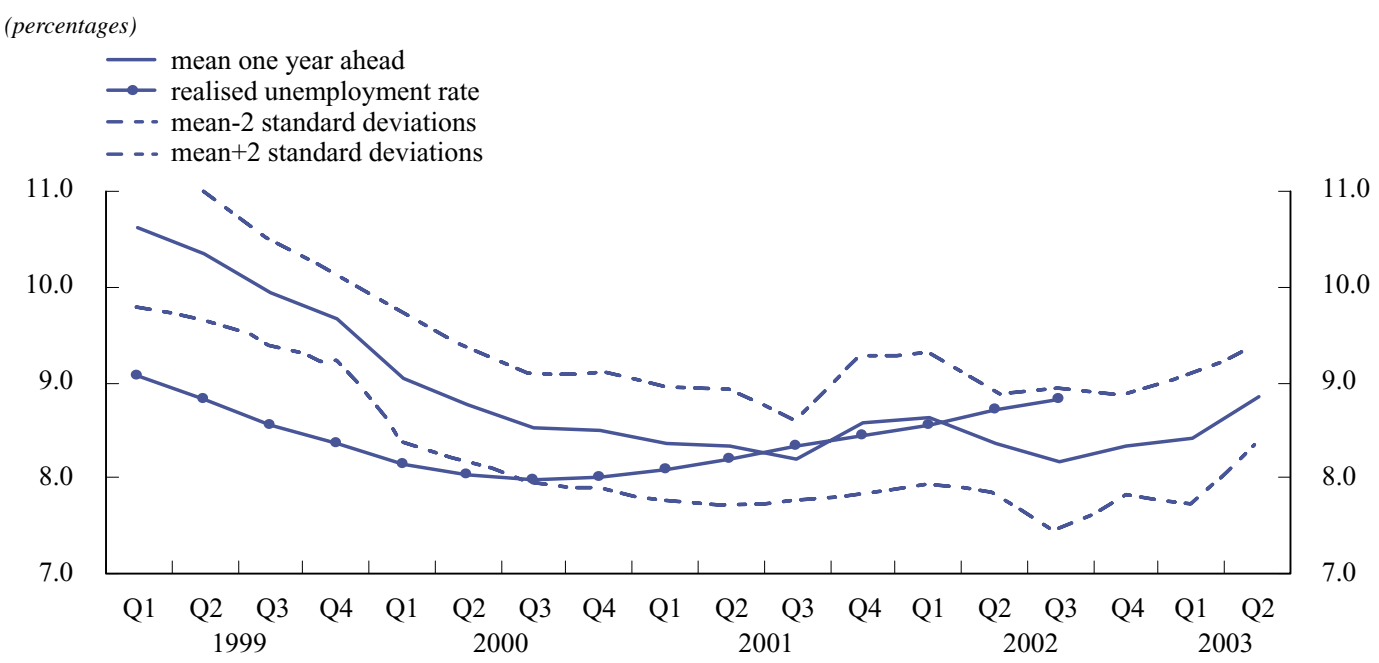

closely tracked the movements in the unemployment rate in the euro area (see Chart 14). The realised values lie clearly outside the uncertainty bands in the first survey rounds only. In fact, the realised values turned out to be significantly lower than expected. This could be partly related to the underestimation of real GDP growth rates as shown in Chart II.

\section{The relationships between the expectations for the different variables: a tentative exploration}

As argued before, to gain a better understanding of the developments in inflation expectations, it may be useful to place them in the context of the prospects for the overall economy. Indeed, this is the main reason why survey participants are asked to provide, together with their expectations for annual HICP inflation rates, their expectations for the year-on-year percentage change in euro area real GDP and for the euro area unemployment rate for the same horizons as for the HICP inflation forecasts. Although the available sample is still too short for a thorough analysis of the links between the expectations collected for the three variables requested, this section provides some illustrative examples of what can be inferred from a comparison of the expectations for the different variables.
First, Chart 15 shows the relationship between the expected inflation rate and real GDP growth at both one-year-ahead and two-yearsahead horizons. The trend lines mapping the expectations for the two variables have a slightly positive slope, suggesting as expected that higher growth prospects tend to be associated with higher inflation rates, although the relationship does not seem to be very strong. Interestingly, however, this relationship seems to be remarkably similar at both oneyear-ahead and two-years-ahead horizons, which may suggest that survey participants have a fairly stable relationship in mind when formulating their expectations.

An idea about how expectations for the different variables have co-moved can be obtained by looking at the correlation between the two series of expectations. The correlation between the expectations for the 


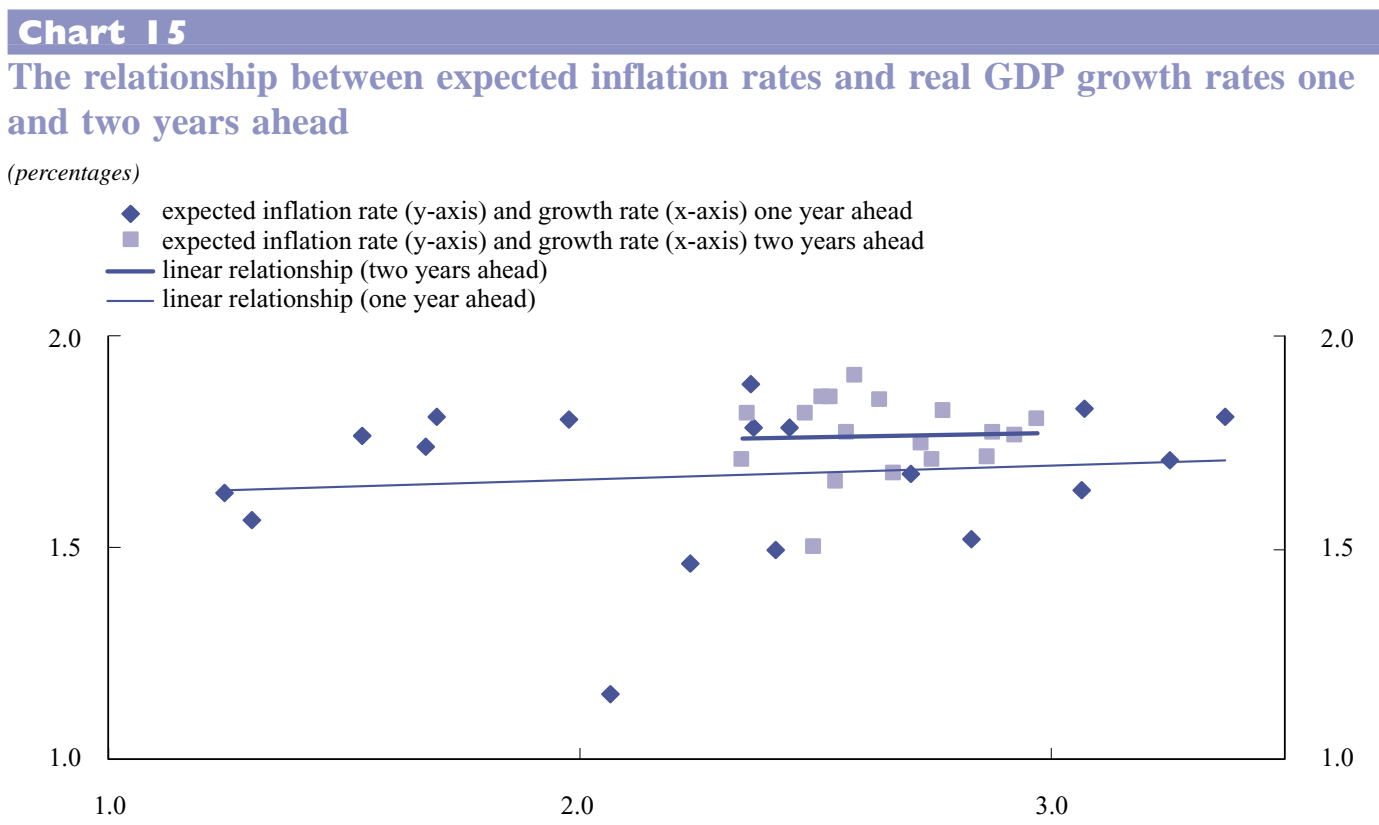

HICP inflation rate and for the real GDP upward revision to the long-term inflation rate growth rate is positive but relatively low at 0.13 at the one-year-ahead horizon, while it is negligible at the two-years-ahead horizon. However, a stronger and negative correlation of -0.71 is found between the longer-term expectations for both variables. It is not straightforward to interpret such a correlation. It may reflect the fact that the gradual downward, although rather limited, movement in long-term growth expectations shown in Chart 12 has simply coincided in the very short sample available with a slight

from 200I. However, each of these slight changes seems to be related to very different factors.

Another issue of interest from a macroeconomic point of view is how participants gauge the relationship between economic activity and the unemployment rate in the euro area. In the sample available to date, expectations for real GDP growth and the unemployment rate do not exhibit a close correlation. At the one-year-ahead horizon the

\section{Chart 16}

The relationship between revisions to the expected real GDP growth rate and revisions to the expected unemployment rate one year ahead

(percentage points)

- revisions to the expected growth rate (x-axis) and to the expected unemployment rate (y-axis) one year ahead linear relationship

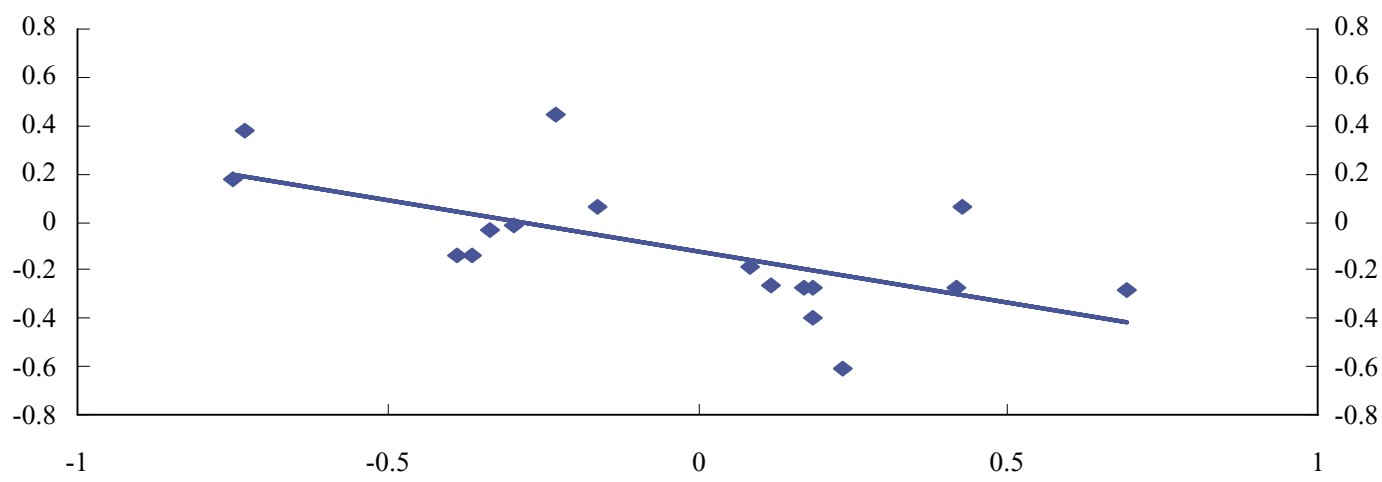


correlation is negligible, at 0.05 . A somewhat higher and negative correlation is, however, obtained at longer horizons: at the two-yearsahead horizon the expectations for the unemployment rate and real GDP growth exhibit a correlation of -0.12 , while the correlation between the series of longer-term expectations is -0.25 .

Given that the unemployment rate in the euro area is expected to follow a clear downward trend over the medium term (for example due to demographic factors), it is also interesting to look at the relationship between the revisions to growth prospects and the revisions to the unemployment rate. Positive revisions to the growth rate one year ahead have tended to be associated with downward revisions to the unemployment rate over the same horizon, and vice versa, as suggested by the negative slope of the trend line depicted in Chart 16. Moreover, the correlation between the revisions to the expectations for both variables is -0.64 , substantially higher than in the case of the point estimates. 


\section{Concluding remarks}

The ECB decided to launch a survey of expectations for the main macroeconomic variables in the euro area in early 1999 and this survey has become known as the ECB's Survey of Professional Forecasters (SPF). The main purpose of this paper was to describe the survey in some detail so that anyone interested in using the results of the survey is aware of the main characteristics of the data. A brief summary of the survey results is currently published in a regular box in the ECB's Monthly Bulletin soon after the survey rounds have been completed. From October 2003, the aggregate results for the most recent survey round will appear simultaneously in a box in the Monthly Bulletin and on the SPF webpages in the Statistics section of the ECB's website (http://www.ecb.int/stats/spf). The historical dataset comprising the aggregate results of all survey rounds conducted to date will also be available on the SPF webpages from October 2003.
This paper has also illustrated some of the information that can be obtained from the aggregate survey results. The aim of the relatively simple analysis of the SPF data presented in Section IV was to inform potential users about the nature of the SPF dataset. In fact, this is the main reason why the ECB has decided to make the dataset of aggregate results freely available. The sample is currently still too small for thorough econometric analysis, but given the relative scarcity of similar datasets in the euro area, it is likely that economists and researchers will increasingly use the results of the ECB's SPF as a basic source for inflation expectations in particular and macroeconomic expectations in general. The ECB would like to encourage such initiatives and looks forward to seeing the results in the near future. 


\section{Annex I}

\section{Changes in the uncertainty surrounding the mean expectations over time}

An additional piece of information that can be obtained from the SPF data is how uncertainty may have evolved over time. Given the specific characteristics of the SPF, in particular the fact that it was launched in 1999 at the beginning of Stage Three of Economic and Monetary Union, it is of interest to see whether significant changes in uncertainty have taken place. This annex reviews the changes in the standard deviation of the point estimates reported by the survey participants ${ }^{20}$ for the three rolling horizons requested, i.e. one, two and five years ahead, and does so for each of the three variables.

With regard to the HICP inflation rate, the standard deviation for the one and two-yearsahead point estimates has remained fairly constant around a mean value of slightly below 0.3 , which may suggest a fairly common understanding among survey participants of the factors effecting changes in the HICP inflation rate, at least in the period under consideration. $^{21}$ Interestingly, there seems to be a lower degree of disagreement for expectations about the long-term inflation rate when compared with the shorter-term horizons. This could be explained by the presence of a higher level of disagreement among survey participants in their assessment of the impact of the temporary shocks that have hit the euro area inflation rate since 1999 than with respect to the long-term value of inflation. Furthermore, there seems to be a significant decrease in the level of uncertainty associated with the longer-term inflation expectations from 200I onwards compared with the observations available in the first two years. The relatively high inflation rates in 2001 and 2002 as a result of temporary shocks affected neither the point estimate for long-term expectations, nor the uncertainty surrounding it, suggesting a sound and even growing credibility of the ECB's commitment to price stability.

20 This is just one of the measures of uncertainty that can potentially be considered for the ECB's SPF data. It was chosen for the present paper on the basis of its transparency and relative lack of complexity. Strictly speaking, the standard deviation of the individual point estimates can be considered as an indicator of the level of disagreement among survey participants on the most likely outcome for the variable and horizon in question. Again, for a recent discussion of this and alternative measures of uncertainty in survey data, see Giordani and Soderlind (2003) and the references therein.

21 The substantial increase in the uncertainty associated with the two-years-ahead expectations in the last survey round is likely to be $a$ one-off event. Such a level of disagreement is highly unusual for any horizon and is not easy to interpret.

\section{Chart A}

Changes in the standard deviation of the individual point estimates for HICP inflation one, two and five years ahead

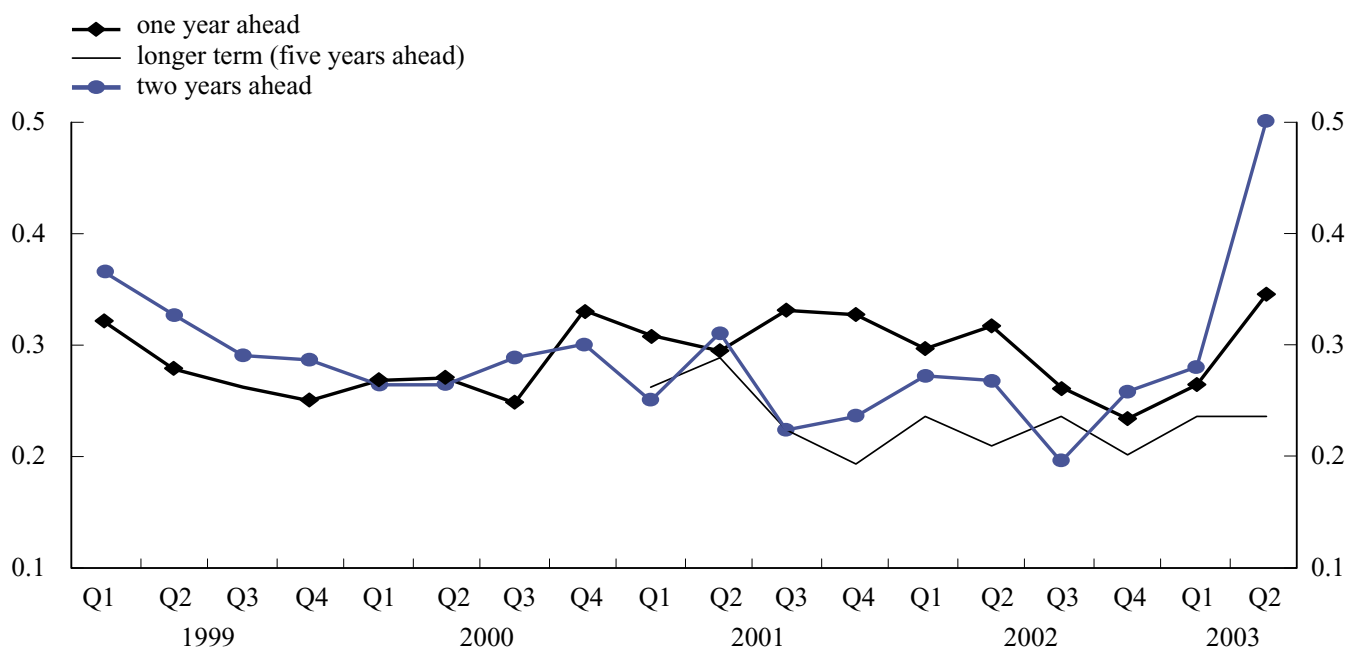




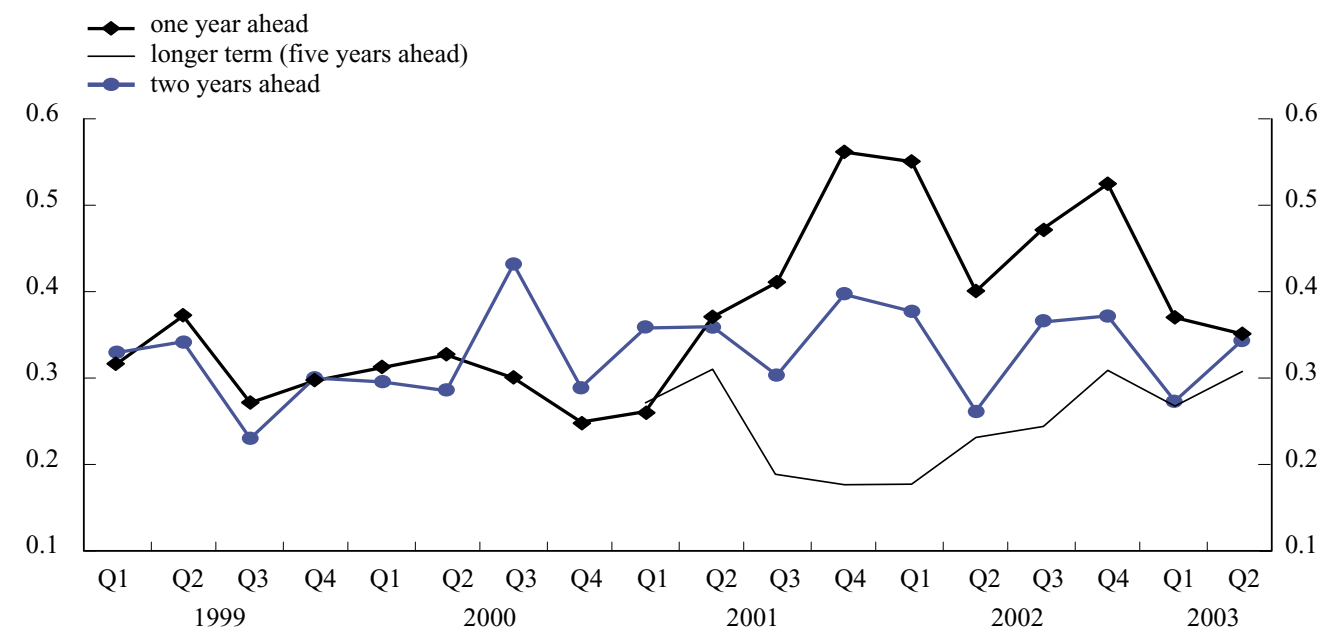

The uncertainty surrounding the expectations for the real GDP growth rate has remained at marginally higher levels, slightly above 0.3 , than that for the inflation expectations when the two and five-years-ahead horizons are considered. Moreover, for these two horizons uncertainty has remained fairly stable around the previously mentioned mean value (see Chart B). By contrast, some significant changes are noticeable in the uncertainty surrounding expectations of real GDP growth one year ahead in the first four years of the survey.
Two different periods can be considered: up to 200I Q3 uncertainty fluctuated around a mean value of approximately 0.3 , comparable with that for the other horizons and the inflation rate; however, from the 200I Q4 SPF uncertainty seems to have increased significantly, to the extent that the average from that survey round was about 0.5 .

Interestingly, within the second sub-period uncertainty surrounding expectations for real GDP growth seems to have risen to its

\section{Chart C}

Changes in the standard deviation of the individual point estimates for the unemployment rate one, two and five years ahead

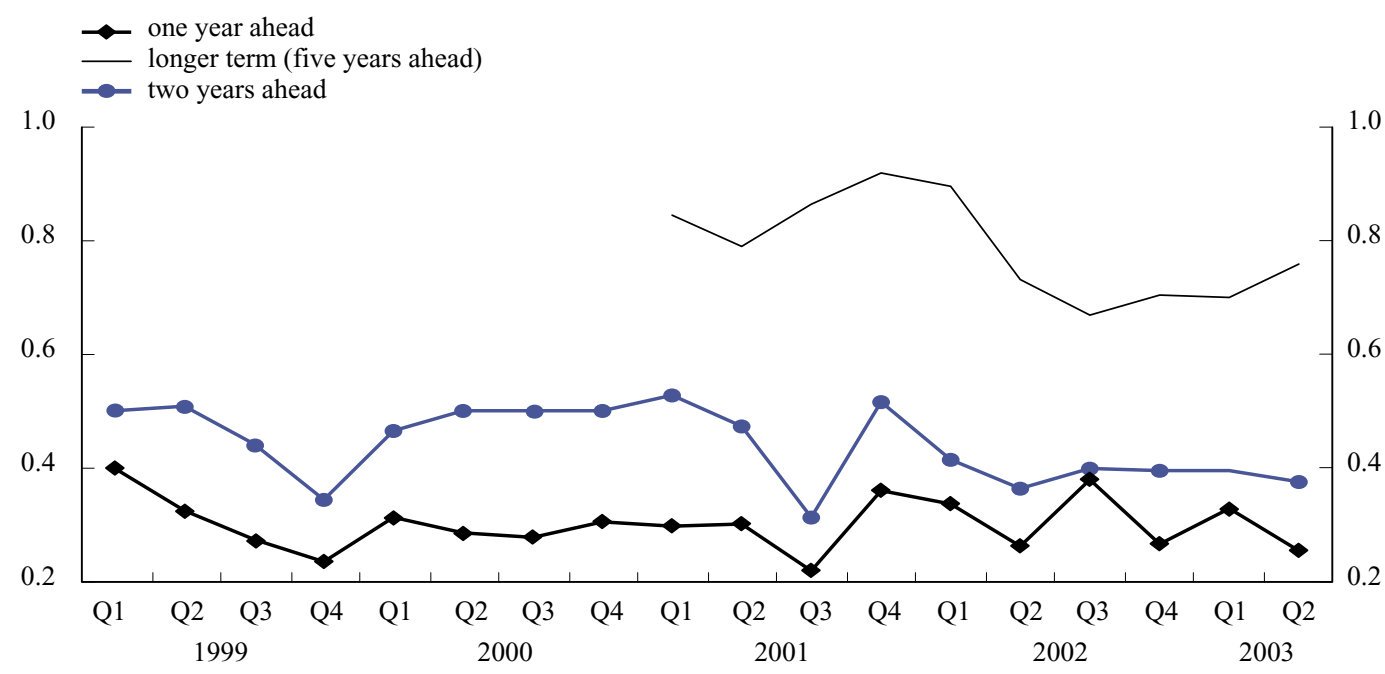


maximum levels around the 200I Q4 and 2002 Q4 survey rounds. In the first case (the 200 I Q4 SPF), the increase in uncertainty appears to be clearly related to the uncertainty about the impact of the September II events on the world economy as a whole and on the euro area in particular. This survey round was conducted in the second half of October 200I. At that time, there were hardly any hard data available and it is logical to assume that survey participants incorporated a substantial amount of judgement into their forecasts, which led to an unusually high degree of disagreement among them, in particular about the shortterm outlook. Uncertainty decreased towards mid-2002, but the geopolitical tensions leading up to the Iraq conflict seemed to push it substantially higher towards the end of 2002. Once these geopolitical tensions diminished, the level of uncertainty seemed to gradually return towards more usual levels.

The level of uncertainty surrounding the expectations for the unemployment rate seems to be more clearly related to the length of the forecast horizon. For expectations one year ahead, it has fluctuated around a standard deviation of 0.3 , and for expectations two years ahead it has been slightly above 0.4, while for longer-term unemployment expectations it has remained higher, at around 0.8 . 


\section{Other available surveys similar to the ECB's SPF}

This annex briefly describes some of the most important surveys of macroeconomic expectations available for the euro area so that the reader can easily compare them with the features of the ECB's SPF. In addition, some basic information on similar surveys conducted for the US economy is also provided.

The European Commission Consumer Survey is a harmonised survey reporting, among other things, assessments of future price developments. It is conducted on a monthly basis on a very large sample (approximately 21,000 households are surveyed every month per country). The responses to the survey are qualitative rather than quantitative and therefore the survey results are reported as percentages of the respondents in each response category, along with the "balance statistic". Although there are some methods to convert the percentage shares of responses in each category into quantitative expectation values for future price developments, such inflation expectations are also based on certain critical assumptions and therefore present a somewhat similar problem to the inflation expectations extracted from asset prices.

Consensus Economics, founded in 1989, is a leading international survey organisation that polls forecasts from more than 400 professional economists from around the world on a monthly basis. These surveys cover estimates for the principal macroeconomic variables (including GDP growth, inflation and interest rates) in over 70 countries. The forecasts are compiled into a series of publications specifically devoted to the world's major industrialised countries and to the emerging economies of the Asia-Pacific region, Latin America and Eastern Europe. These publications report consensus forecasts (a simple arithmetic average of all of the individual predictions collected by Consensus Economics for a single economic indicator in a monthly survey), as well as the predictions of individual forecasters. Regarding the euro area, they provide aggregates for the reported expectations for each member country's GDP growth rate and consumer price inflation as measured by the Consumer Price Index (CPI). These national CPI-based inflation expectations for the euro area produced by Consensus Economics were an imperfect indicator of inflation expectations in the euro area for the purpose of the ECB's monetary policy strategy, in which price stability for the euro area is defined in terms of the HICP. Fortunately, since January 2003 forecasts for the euro area HICP and euro area real GDP growth have also been included in the Consensus Economics questionnaire. In terms of the horizons, the expectations refer to the average for the current and the next calendar year, and long-term expectations are requested twice a year in the April and October issues.

\section{Existing surveys for the US economy}

Although several surveys of macroeconomic expectations are conducted for the US economy, the focus here will be on the surveys that are similar to the ECB's SPF, namely the two surveys of expectations for the US economy currently conducted by the Federal Reserve Bank of Philadelphia.

The Livingston Survey was started in 1946 by the economist and columnist for the Philadelphia Inquirer, Joseph Livingston, from whom the survey took its name. It is the oldest continuous survey of economists' expectations. It summarises the forecasts of economists from industry, government, banking and academia. The Philadelphia Fed took responsibility for the survey in 1990. The survey is conducted twice a year, in June and December, and consists of forecasts of 18 different variables describing national output, prices, unemployment and other macroeconomic data. For 16 of the 18 variables, the respondents supply forecasts for the levels of the variables at five different horizons, including long-run horizons. The survey results, consisting of the average 
(mean) forecast of each variable, are reported in the Philadelphia Inquirer and other news media and are also available from the Philadelphia Fed. These data have been used in numerous research papers and an extensive list of these papers can be found on the website of the Philadelphia Fed (http://www.phil.frb.org).

The Survey of Professional Forecasters (SPF) of the Federal Reserve Bank of Philadelphia ${ }^{22}$ is the most similar to the ECB's SPF. The American Statistical Association (ASA), together with the National Bureau of Economic Research (NBER), began conducting a survey in the fourth quarter of 1968. It became called the ASA/NBER Economic Outlook Survey. In the early days the survey attracted many forecasters (over 50 in the first years) but later on the number of participants declined, and the ASA and the NBER decided to discontinue the survey. Later, in 1990, the Philadelphia Fed revived the survey with approximately 30 participants.

In the first survey (1968 Q4) participants were asked to forecast ten variables for the next five quarters. The survey was restructured in 1981, and annual forecasts were added. Currently there are 27 different variables included in the survey questionnaire.
The forecasters are also asked to report probability variables and long-term forecasts. In addition to these specific variables for which there is a quantitative response survey, participants are asked for the factors that affect their forecasts and, occasionally, about some specific topic that is not reflected in the other questions of the survey.

The survey participants come mainly from the business world and Wall Street. For example, out of 36 participants in one of the rounds, 13 were from Wall Street financial firms, 8 from banks, 5 from economic consulting firms, 3 from university research centres and 7 from other private firms. In all the publications using the Philadelphia Fed's SPF data, forecasters' anonymity is preserved by means of identifying each participant by a code. The data have also been used in numerous research papers and an extensive list of these can be found on the Philadelphia Fed's website.

22 For additional details of the Philadelphia Fed's SPF, please see the article "Introducing: the Survey of Professional Forecasters" by Dean Croushore, from which this annex largely draws and which can be found on the Philadelphia Fed website (http://www.phil.frb.org/econ/spf/index.html). 


\section{Annex III}

\section{Historical values of the mean point estimates and the aggregate results of the 2003 Q2 SPF}

This annex shows the SPF data that can be found in the Statistics section of the ECB's website (http://www.ecb.int/stats/spf).

\section{Table A}

Historical values of the mean point estimates by variable

(HICP inflation ${ }^{l)}$ forecasts: mean point estimates)

\begin{tabular}{|c|c|c|c|c|c|c|c|}
\hline \multicolumn{2}{|c|}{$\begin{array}{l}\text { Survey } \\
\text { round }\end{array}$} & \multirow{2}{*}{$\begin{array}{c}\begin{array}{c}\text { Current } \\
\text { calendar } \\
\text { year }\end{array} \\
1.0\end{array}$} & \multirow{2}{*}{$\begin{array}{c}\begin{array}{c}\text { Next } \\
\text { calendar } \\
\text { year }\end{array} \\
1.3\end{array}$} & \multirow[t]{2}{*}{$\begin{array}{l}\text { Calendar } \\
\text { year } \\
\text { after next }\end{array}$} & \multirow{2}{*}{$\begin{array}{c}\begin{array}{c}\text { One year } \\
\text { ahead }\end{array} \\
1.2\end{array}$} & \multirow{2}{*}{$\begin{array}{c}\begin{array}{c}\text { Two years } \\
\text { ahead }\end{array} \\
1.5\end{array}$} & \multirow{2}{*}{$\begin{array}{c}\begin{array}{c}\text { Longer term } \\
\text { (five years } \\
\text { ahead) }\end{array} \\
1.9\end{array}$} \\
\hline 1999 & Q1 & & & & & & \\
\hline & Q2 & 1.1 & 1.5 & & 1.5 & 1.7 & \\
\hline & Q3 & 1.1 & 1.5 & & 1.5 & 1.7 & \\
\hline & Q4 & 1.1 & 1.5 & & 1.5 & 1.7 & \\
\hline 2000 & Q1 & 1.7 & 1.7 & & 1.6 & 1.7 & 1.8 \\
\hline & Q2 & 1.9 & 1.8 & & 1.7 & 1.8 & \\
\hline & Q3 & 2.1 & 1.8 & 1.8 & 1.8 & 1.8 & \\
\hline & Q4 & 2.3 & 2.0 & 1.8 & 1.8 & 1.8 & \\
\hline 2001 & Q1 & 2.0 & 1.7 & & 1.7 & 1.7 & 1.8 \\
\hline & Q2 & 2.3 & 1.8 & & 1.8 & 1.8 & 1.8 \\
\hline & Q3 & 2.7 & 1.9 & 1.8 & 1.8 & 1.8 & 1.8 \\
\hline & Q4 & 2.6 & 1.7 & 1.8 & 1.6 & 1.8 & 1.8 \\
\hline 2002 & Q1 & 1.7 & 1.8 & & 1.7 & 1.8 & 1.9 \\
\hline & Q2 & 2.1 & 1.9 & & 1.9 & 1.9 & 1.9 \\
\hline & Q3 & 2.1 & 1.8 & 1.9 & 1.8 & 1.9 & 1.9 \\
\hline & Q4 & 2.2 & 1.8 & 1.9 & 1.8 & 1.9 & 1.9 \\
\hline 2003 & Q1 & 1.8 & 1.8 & & 1.8 & 1.8 & 1.9 \\
\hline & Q2 & 2.0 & 1.7 & & 1.6 & 1.7 & 1.9 \\
\hline
\end{tabular}

I) Inflation is defined on the basis of the Harmonised Index of Consumer Prices published by Eurostat.

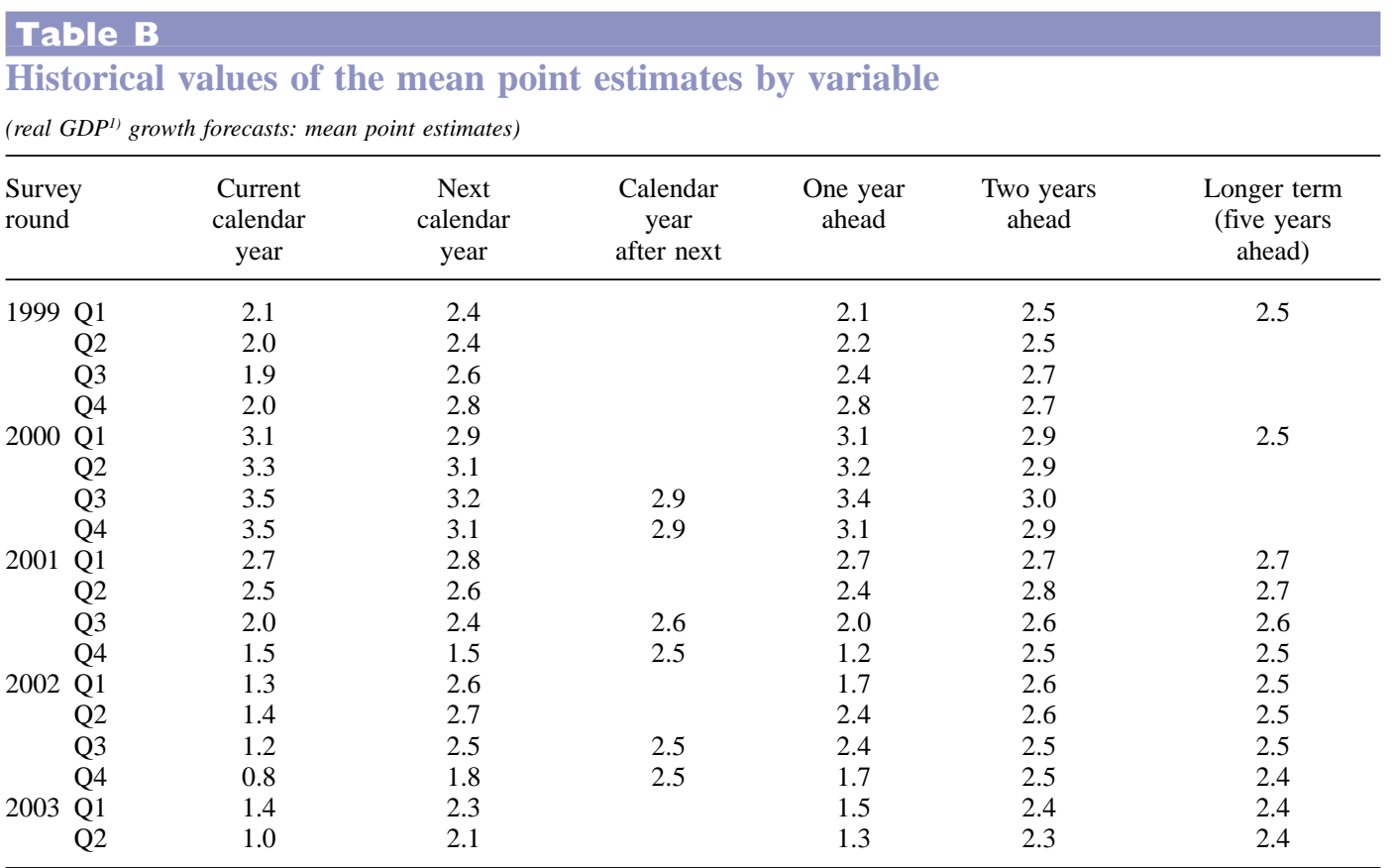

I) GDP is defined on the basis of the standardised ESA 95 definition published by Eurostat. 
Table C

Historical values of the mean point estimates by variable

\begin{tabular}{|c|c|c|c|c|c|c|c|}
\hline \multicolumn{2}{|c|}{$\begin{array}{l}\text { Survey } \\
\text { round }\end{array}$} & \multirow{2}{*}{$\begin{array}{c}\begin{array}{c}\text { Current } \\
\text { calendar } \\
\text { year }\end{array} \\
10.7\end{array}$} & \multirow{2}{*}{$\begin{array}{c}\begin{array}{c}\text { Next } \\
\text { calendar } \\
\text { year }\end{array} \\
10.5\end{array}$} & \multirow[t]{2}{*}{$\begin{array}{l}\text { Calendar } \\
\text { year } \\
\text { after next }\end{array}$} & \multirow{2}{*}{$\begin{array}{c}\begin{array}{c}\text { One year } \\
\text { ahead }\end{array} \\
10.6\end{array}$} & \multirow{2}{*}{$\begin{array}{c}\begin{array}{c}\text { Two years } \\
\text { ahead }\end{array} \\
10.3\end{array}$} & \multirow{2}{*}{$\begin{array}{c}\begin{array}{c}\text { Longer term } \\
\text { (five years } \\
\text { ahead) }\end{array} \\
9.5\end{array}$} \\
\hline 1999 & Q1 & & & & & & \\
\hline & Q2 & 10.5 & 10.2 & & 10.3 & 9.9 & \\
\hline & Q3 & 10.3 & 9.9 & & 9.9 & 9.6 & \\
\hline & Q4 & 10.2 & 9.7 & & 9.7 & 9.2 & \\
\hline 2000 & Q1 & 9.3 & 8.8 & & 9.1 & 8.6 & 8.1 \\
\hline & Q2 & 9.2 & 8.6 & & 8.8 & 8.3 & \\
\hline & Q3 & 9.1 & 8.4 & 8.0 & 8.5 & 8.1 & \\
\hline & Q4 & 9.1 & 8.5 & 8.1 & 8.5 & 8.1 & \\
\hline 2001 & Q1 & 8.6 & 8.1 & & 8.4 & 8.0 & 7.2 \\
\hline & Q2 & 8.5 & 8.2 & & 8.3 & 8.0 & 7.3 \\
\hline & Q3 & 8.4 & 8.2 & 7.9 & 8.2 & 7.9 & 7.1 \\
\hline & Q4 & 8.4 & 8.6 & 8.2 & 8.6 & 8.2 & 7.2 \\
\hline 2002 & Q1 & 8.6 & 8.4 & & 8.6 & 8.3 & 7.3 \\
\hline & Q2 & 8.5 & 8.2 & & 8.4 & 8.0 & 7.2 \\
\hline & Q3 & 8.4 & 8.1 & 7.8 & 8.2 & 7.8 & 7.1 \\
\hline & Q4 & 8.3 & 8.4 & 8.0 & 8.3 & 7.9 & 7.2 \\
\hline 2003 & Q1 & 8.5 & 8.2 & & 8.4 & 8.1 & 7.1 \\
\hline & Q2 & 8.8 & 8.7 & & 8.9 & 8.5 & 7.5 \\
\hline
\end{tabular}

I) Unemployment is defined on the basis of the standardised definition published by Eurostat.

Table D

Mean point estimates and probability distributions for HICP inflation ${ }^{1)}$ (survey round: 2003 Q2 SPF)

\begin{tabular}{lccccc}
\hline & 2003 & 2004 & Mar. 2004 & Mar. 2005 & 2007 \\
\hline Mean point estimate & 2.0 & 1.7 & 1.6 & 1.7 & 1.9 \\
Standard deviation & 0.2 & 0.3 & 0.3 & 0.5 & 0.2 \\
Number of replies & 53 & 52 & 48 & 42 & 40 \\
\hline
\end{tabular}

\begin{tabular}{|c|c|c|c|c|c|}
\hline Probability distributions & 2003 & 2004 & Mar. 2004 & Mar. 2005 & 2007 \\
\hline$<0.0 \%$ & 0.0 & 0.1 & 0.1 & 1.8 & 0.5 \\
\hline $0.0-0.4 \%$ & 0.1 & 1.1 & 1.5 & 2.3 & 1.2 \\
\hline $0.5-0.9 \%$ & 0.8 & 5.6 & 8.7 & 5.6 & 4.8 \\
\hline $1.0-1.4 \%$ & 7.6 & 19.5 & 27.5 & 18.6 & 13.9 \\
\hline $1.5-1.9 \%$ & 38.5 & 45.7 & 36.1 & 40.5 & 40.9 \\
\hline $2.0-2.4 \%$ & 43.5 & 21.2 & 19.5 & 22.2 & 25.2 \\
\hline $2.5-2.9 \%$ & 8.2 & 4.8 & 4.5 & 5.9 & 8.8 \\
\hline $3.0-3.4 \%$ & 1.3 & 1.5 & 1.6 & 2.4 & 3.3 \\
\hline \multirow[t]{2}{*}{$3.5 \%$} & 0.1 & 0.4 & 0.5 & 0.7 & 1.4 \\
\hline & 100 & 100 & 100 & 100 & 100 \\
\hline
\end{tabular}

I) Annual percentage changes. Inflation is defined on the basis of the Harmonised Index of Consumer Prices published by Eurostat. 
Table E

Mean point estimates and probability distributions for real GDP growth ${ }^{1)}$

(survey round: 2003 Q2 SPF)

\begin{tabular}{lccccc}
\hline & 2003 & 2004 & $2004 \mathrm{Q} 4$ & $2005 \mathrm{Q} 4$ & 2007 \\
\hline Mean point estimate & 1.4 & 2.3 & 1.5 & 2.4 & 2.4 \\
Standard deviation & 0.3 & 0.2 & 0.4 & 0.3 & 0.3 \\
Number of replies & 56 & 54 & 54 & 51 & 46 \\
\hline
\end{tabular}

\begin{tabular}{|c|c|c|c|c|c|}
\hline Probability distributions & 2003 & 2004 & 2004 Q4 & 2005 Q4 & 2007 \\
\hline$<0.0 \%$ & 0.7 & 0.5 & 1.3 & 0.9 & 0.5 \\
\hline $0.0-0.4 \%$ & 7.0 & 1.2 & 5.6 & 1.4 & 0.8 \\
\hline $0.5-0.9 \%$ & 36.2 & 4.1 & 25.6 & 4.0 & 2.8 \\
\hline $1.0-1.4 \%$ & 40.4 & 11.1 & 33.4 & 7.4 & 7.9 \\
\hline $1.5-1.9 \%$ & 11.1 & 29.4 & 22.1 & 17.4 & 16.3 \\
\hline $2.0-2.4 \%$ & 3.1 & 34.8 & 8.3 & 31.8 & 32.0 \\
\hline $2.5-2.9 \%$ & 1.2 & 14.3 & 2.7 & 25.3 & 26.2 \\
\hline $3.0-3.4 \%$ & 0.3 & 3.1 & 0.7 & 9.1 & 8.8 \\
\hline $3.5-3.9 \%$ & 0.1 & 1.1 & 0.2 & 1.7 & 3.8 \\
\hline \multirow[t]{2}{*}{$4.0 \%$} & 0.0 & 0.4 & 0.1 & 0.9 & 0.9 \\
\hline & 100 & 100 & 100 & 100 & 100 \\
\hline
\end{tabular}

1) Annual percentage changes. GDP is defined on the basis of the standardised ESA 95 definition published by Eurostat.

\section{Table F}

Mean point estimates and probability distributions for the euro area unemployment rate ${ }^{1)}$

(survey round: 2003 Q2 SPF)

\begin{tabular}{lccccc}
\hline & 2003 & 2004 & Feb. 2004 & Feb. 2005 & 2007 \\
\hline Mean point estimate & 8.8 & 8.7 & 8.9 & 8.5 & 7.5 \\
Standard deviation & 0.2 & 0.3 & 0.3 & 0.4 & 0.8 \\
Number of replies & 50 & 49 & 43 & 37 & 36 \\
\hline
\end{tabular}

\begin{tabular}{|c|c|c|c|c|c|}
\hline Probability distributions & 2003 & 2004 & Feb. 2004 & Feb. 2005 & 2007 \\
\hline$<5.5 \%$ & 0.0 & 0.0 & 0.0 & 0.0 & 0.6 \\
\hline $5.5-5.9 \%$ & 0.0 & 0.0 & 0.0 & 0.0 & 2.1 \\
\hline $6.0-6.4 \%$ & 0.0 & 0.1 & 0.0 & 0.0 & 7.3 \\
\hline $6.5-6.9 \%$ & 0.1 & 0.3 & 0.1 & 0.3 & 11.9 \\
\hline $7.0-7.4 \%$ & 0.5 & 1.7 & 0.7 & 3.5 & 19.9 \\
\hline $7.5-7.9 \%$ & 2.8 & 6.6 & 3.6 & 11.0 & 23.6 \\
\hline $8.0-8.4 \%$ & 12.5 & 15.0 & 15.0 & 24.6 & 19.4 \\
\hline $8.5-8.9 \%$ & 52.9 & 45.6 & 43.0 & 38.1 & 9.5 \\
\hline $9.0-9.4 \%$ & 27.7 & 24.8 & 31.2 & 17.7 & 3.7 \\
\hline $9.5-9.9 \%$ & 3.1 & 4.7 & 5.2 & 3.7 & 1.4 \\
\hline $10.0-10.4 \%$ & 0.2 & 0.8 & 0.9 & 1.0 & 0.7 \\
\hline $10.5-10.9 \%$ & 0.0 & 0.2 & 0.2 & 0.1 & 0.1 \\
\hline \multirow[t]{2}{*}{$11.0 \%$} & 0.0 & 0.1 & 0.0 & 0.0 & 0.0 \\
\hline & 100 & 100 & 100 & 100 & 100 \\
\hline
\end{tabular}

I) As a percentage of the labour force. Unemployment is defined on the basis of the standardised definition published by Eurostat. 


\section{References}

Commission of the European Communities (1997), "The joint harmonised EU programme of business and consumer surveys", European Economy, No. 6, Brussels.

Croushore, D. (1993), "Introducing: the Survey of Professional Forecasters", Business Review, November/December, Federal Reserve Bank of Philadelphia, Philadelphia.

Deutsche Bundesbank (200I), "The information content of survey data on expected price developments for monetary policy", Monthly Report, January, Frankfurt am Main.

ECB (2000), "The information content of interest rates and their derivatives for monetary policy”, Monthly Bulletin, May, Frankfurt am Main.

ECB (2002a), "Deriving long-term euro area inflation expectations from index-linked bonds issued by the French Treasury", Monthly Bulletin, February, Frankfurt am Main.

ECB (2002b), "The clustering of shocks to HICP inflation since the start of Stage Three of EMU", Monthly Bulletin, June, Frankfurt am Main.

ECB (2003), "The outcome of the ECB's evaluation of its monetary policy strategy", Monthly Bulletin, June, Frankfurt am Main.

Forsells, M. and G. Kenny (2002), "The rationality of consumers' inflation expectations: survey-based evidence for the euro area", ECB Working Paper series No. 163, Frankfurt am Main.

Giordani, P. and P. Soderlind (2003), "Inflation forecast uncertainty", forthcoming in European Economic Review. 


\section{European Central Bank \\ Occasional Paper Series}

I "The impact of the euro on money and bond markets" by J. Santillán, M. Bayle and C. Thygesen, July 2000.

2 "The effective exchange rates of the euro" by L. Buldorini, S. Makrydakis and C. Thimann, February 2002.

3 "Estimating the trend of $M 3$ income velocity underlying the reference value for monetary growth" by C. Brand, D. Gerdesmeier and B. Roffia, May 2002.

4 "Labour force developments in the euro area since the 1980s" by V. Genre and R. GómezSalvador, July 2002.

5 "The evolution of clearing and central counterparty services for exchange-traded derivatives in the United States and Europe: a comparison" by D. Russo, T.L. Hart and A. Schönenberger, September 2002.

6 "Banking integration in the euro area" by I. Cabral, F. Dierick and J. Vesala, December 2002.

7 "Economic relations with regions neighbouring the euro area in the "euro time zone" by F. Mazzaferro, A. Mehl, M. Sturm, C. Thimann and A. Winkler, December 2002.

8 "An introduction to the ECB's survey of professional forecasters" by J.A. Garcia, September 2003. 



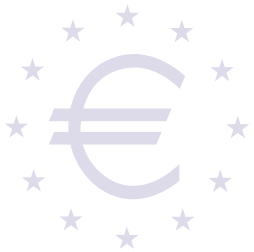

